\title{
Joint estimation of sequential labor force participation and fertility decisions using Markov chain Monte Carlo techniques*
}

\author{
Kenneth R. Troske ${ }^{\dagger} \quad$ Alexandru Voicu ${ }^{\ddagger}$
}

August 19, 2004

\begin{abstract}
In this paper we estimate the causal effect of children on the labor supply of women using panel data on women from the 1979 National Longitudinal Survey of Youth (NLSY79). We examine the effect of children both prior to and after birth as well as how the effect of children varies with the number of children. We also decompose the total effect of children into the direct and indirect components and separately examine the dynamics of these components. Sequential participation decisions for four levels of labor market involvement and fertility decisions are jointly modeled. We allow decisions to be correlated in a general fashion both across time and across choices. The estimation is performed using Markov chain Monte Carlo methods. We find that children have a strong effect on a women's labor market behavior in the post-birth period and that differences in expected fertility have a strang effect on labor market behavior in the pre-birth period. We also find that both the direct and indirect effects are large immediately after the birth of a child but that the indirect effect declines quickly over time. The effects of children vary by education and race.

Keywords: Female Labor Supply, Multivariate Probit Model, Gibbs Sampler.

JEL codes: C11,C15, J13, J22

${ }^{*}$ We would like to thank Saku Aura, Emek Basker, and Barton Hamilton for helpful comments, and Hielke Buddelmeyer for his help in creating the data set. We are especially grateful to Peter Mueser for numerous helpful comments on an earlier draft of this paper. This reasearch was begun when Troske was a visiting fellow at IZA and he would like to thank them for generous financial support. All remaining errors are our own.

${ }^{\dagger}$ University of Missouri-Columbia and IZA, Bonn
\end{abstract}

$\ddagger$ IZA, Bonn 


\section{Introduction}

Estimating the effect children have on women's labor supply has a long and varied history in economics. ${ }^{1}$ One of the main insights from this research is that, given the dynamic nature of the problem, estimating the effect of fertility on the dynamics of female labor supply is an extremely difficult problem. Both the number and timing of children are variables that are controlled, at least in part, by women. Heterogeneity in the demand for children and the taste for work will affect women's investment in human capital long before the birth of any children, which will in turn affect labor supply prior to the birth of children. In addition, children will have both a direct and indirect effect on a women's supply of labor to the market after they are born. The direct effect is a result of children raising the non-market opportunity of women thereby reducing their labor supply. The indirect effect derives from the fact that when women leave the labor market to have children they experience a fall in their investment in human capital and therefore in their propensity to work in the future. Estimating models that are general enough to incorporate all of these elements not only requires panel data, but also requires the use of dynamic response models along with information identifying exogenous variation in the demand for children and the supply of labor.

The goal of this paper is to estimate the effect of children on the dynamic labor supply of women using panel data from the 1979 National Longitudinal Survey of Youth (NLSY79). We use Markov chain Monte Carlo (MCMC) methods to estimate the dynamic labor supply behavior of women, while simultaneously estimating the determinants of fertility. From these estimates we then decompose the effect of fertility on labor supply into the direct and indirect components and examine how these effects vary by personal characteristics. We also use these estimates to examine the effect of expected future fertility on the current labor supply of women.

Our paper extends the recent literature on the effect of children on female labor supply in a number of directions. First, following the suggestion in Browning (1992), we divide our analysis into a pre-birth and a post-birth period and examine the effect of children on women's labor supply in both periods. As far as we know, we are the first to explicitly examine the effect of expected future fertility on women's labor supply. Second, for multiple children, we estimate separate effects for each child. Previous research on the causal effect of children on labor supply has exploited exogenous variation in the second or third child to measure the causal effect of children (e.g. Carrasco, 2001; Angrist and Evans, 1998; Rosenzweig and Wolpin 1980). If, as seems likely to us, the effect of children is declining in the number of children, these previous estimates of the effect of children will understate the effects of the first child. Our estimates should provide a more precise measure of the effect of the first child on a woman's labor supply as well as showing how the effect varies with the number of children. Third, following the suggestions in Browning (1992) and Nakamura

\footnotetext{
${ }^{1}$ Browning (1992) and Nakamura and Nakamura (1992) both provide reviews of the history of this liturature.
} 
and Nakamura (1992) we decompose the total effect of children into the direct and indirect effect and examine how these effects change over time. Fourth, in contrast to the previous papers that model labor market participation using two states (Carrasco, 2001; Angrist and Evans, 1998; Hyslop, 1999; Chib and Jeliazkov, 2003) or three states (Buddlemeyer and Voicu, 2003) we model labor market participation using four states: full time, full time part year, part time and nonparticipation. If one of the primary effects of children on women's labor supply is through the number of hours worked, this four state model allows us to better capture the dynamics of labor market participation. This may be particularly important around the birth of a child (Blank, 1989 and 1998). Finally, we explicitly model and estimate the determinants of fertility.

We also extend the literature on estimating dynamic discrete choice models in two directions. First, through the use of a more general four state multiperiod multinomial probit model with auto-correlated error terms to model labor force decisions, along with a probit model with state dependence and an auto-correlated error term to model fertility decisions. Second, by employing a mixed effects structure that combines fixed and random effects. The mixedeffect structure accomplishes several goals: a) it allows time-invariant individual heterogeneity to simultaneously affect participation and fertility behavior; b) it allows both time invariant tastes for children and the timing of births to vary across individuals; and c) it captures heterogeneity in the dynamics of the level of labor market involvement around birth. The cross-equation correlation of the random coefficients is important for the endogenous modelling of participation and fertility decisions and for the multinomial probit representation of labor market decisions.

We estimate this model using data on women from the NLSY79. Because the NLSY79 data consist of individuals who were 14 to 21 in 1979, we have a fairly complete picture of both these women's labor market and fertility dynamics. In addition, the NLSY79 data contain a rich set of family background variables, such as parent's labor market status and education, and sibling's fertility. These variables, along with the panel structure of the data, help us identify heterogeneity in the taste for and the cost of children across the women in our data.

We find that children affect the labor market dynamics of women in postbirth periods and that expected future fertility affects the labor market dynamics of women in the pre-birth period, with much of the difference in labor market participation prior to birth due to unobserved heterogeneity. We also find that the direct and indirect effects of children are of similar size immediately after birth, but that the indirect effect declines quickly over time, suggesting that the loss of human capital resulting from a woman exiting the labor market to have a child is fairly small. The direct effect declines with the age of children. Both the direct and indirect effects are smaller for the second child than for the first. We find that the size of the direct and indirect effects vary with personal characteristics. Relative to white women, the direct effect of children are smaller for black and Hispanic women. For the first child both the direct and indirect effects are smaller for more educated women, but the opposite is 
true for the second child. Finally, we find that our four state model of labor force participation better captures women's labor force dynamics. There are significant qualitative difference between working full time part year and working full time or part time.

The remainder of the paper is structured as follows. Section 2 contains a theoretical background and a description of the data. The empirical specification, the estimation method, and the estimation results are presented in section 3. In section 4 we describe our pre-birth and post-birth simulations that we use to study the effects of children, we present the formal definition of the direct and indirect effects, and we discuss selected results. Concluding remarks follow.

\section{Theoretical background and data}

The existing literature on women's labor supply suggests two basic facts. First, children have a negative effect on women's labor supply and second, this effect fades away as children grow older. Many different factors account for these findings. Women's physical capacity for performing market work is sharply diminished during the period surrounding birth; rearing children is time-intensive and initially involves a taxing personal and family adjustment process. As children grow, caring for them requires less time and more market choices become available. Families also adjust to the new state. This effect can be formalized and studied using various models. The neoclassical labor supply theory assumes that individuals make employment decisions by comparing the utility of working with the utility of not working. The value of working relative to not working increases as the child ages (Mincer 1962, Heckman 1980, Leibowitz, Klerman, and Waite 1992). In a job-search framework (Mortensen, 1986) the value of time in alternative (non-work) states can be assumed to vary with the number of children and their ages. The birth of the child will raise the value of time in alternative use and, through it, the reservation wage. As a result, the probability of employment will decline.

The second fact is that sequential employment decisions of women are correlated. As a result, labor market interruptions are associated with a decline in the probability of employment in subsequent periods. Heckman and Willis (1977) have defined two sources of dependence: a) unobserved heterogeneity generated by different preferences, and b) state dependence. There are multiple sources of state dependence. Human capital theory predicts that skills accumulated through experience raise the probability of working in the future. Fixed costs of entering the labor force (search costs, for example) make future participation more likely for individuals already working. Job matching models where employers and employees learn about the quality of the match induce state dependence even if investment in firm-specific human capital does not take place.

The presence of state dependence is very important in studying the effect of fertility on labor supply. Maternity-related work interruptions lead to a decline in human capital investment, and possibly to depreciation of the human capital 
stock. Also search costs and information on the quality of the match may be lost. Longer interruptions are more detrimental in the human capital framework.

These two phenomena provide a framework for studying the effect of children on women's labor supply. They imply first that a women's investment in human capital prior to entering the labor market, as well as her labor supply in every period, will be affected by expectations about future fertility. They also imply that a women's post-birth employment likelihood should be driven by the increased demand placed on her time by newborn children and by the length of the maternity-related work interruption. The first component should be fading with a child's age. The second component should be stronger the longer the interruption. In this paper we use the broad labels direct and indirect effects for these two mechanisms. The measures of the direct and the indirect effect depend on the events for which they are measured. In the following sections we describe formally the statistical model we use to estimate the effects of children on women's labor both prior to and after a birth and provide definitions of the direct and indirect effects for particular events.

The data we use in this analysis come from the 1979 National Longitudinal Survey of Youth (NLSY79). The NLSY79 contains a representative sample of individuals between 14 and 21 years old in 1979. These individuals are surveyed every year between 1979 and 1994, and every other year thereafter. We use data from the nonmilitary sample of the 1979-1994 surveys. We restrict the sample to women who are not married and are childless in 1979, get married after 1979, and remain married until 1994, only have children while married, and only have biological children in the household over the period of our data. ${ }^{2}$ We exclude women who live on a farm larger than 100 acres at any point in the period. In order to abstract from the trade-off between schooling and working, we only consider a woman at risk to work or to have a child once she has been out of school for at least 18 months continuously. ${ }^{3}$ Finally, we require at least five years of data for each woman. ${ }^{4}$ This selection results in an unbalanced panel of 880 women observed between 1979 and 1994. Through this selection we ensure that initial conditions are identical across individuals in the sample-all women are childless and have no labor market history in the first period.

The following series of tables and figures provide an overview of some of the main variables used in the analysis. Table 1 presents summary statistics for variables that do not change over time, what we refer to as background variables. The numbers in this table are for all 880 women who are in our sample. Roughly 70 percent of our sample is white, with the remainder evenly split between Hispanic and black. Respondents' fathers tend to work full time while about $1 / 3$ of their mothers work full time and $1 / 3$ do not work at all. ${ }^{5}$

\footnotetext{
${ }^{2}$ This latter criteria eliminates women who adopt children or who marry men who have children who live with them.

${ }^{3}$ Once a women leaves school we consider her still at risk even if she returns to school.

${ }^{4}$ Relaxing this requirements adds 13 more women to the sample and has no effect on our results.

${ }^{5}$ Information about parents are asked in the 1979 survey. Information about labor market status refers to parents' labor market status in 1978.
} 
On average, women in the sample have slightly over three siblings, the siblings have 13 years of schooling on average and siblings' average number of children is $1.3 .^{6}$

Table 2 presents summary statistics, by year, for the time varying variables used in the analysis. ${ }^{7}$ Column 2 , which presents the number of women considered at risk in a given year, shows the unbalanced nature of the data. In 1979 only 169 women are considered at risk, by 1988 all 880 women are considered at risk. This table shows that no women had any children prior to 1981. In 1981 two percent of the at-risk women in the sample had children age 0 to 1 . By 1993, seven percent of the sample had children 10 years old or older, while 37 percent of the sample had children between six and nine years old.

Figure 1 presents the labor market status for all women in the sample in a given year. We measure labor market status using hours worked in a given year, weeks worked in a given year, and income. To be considered working a woman must have both positive hours worked and positive income. Women who worked more than 1750 hours in a year are classified as full time. Women who work between zero and 1750 hours, but who work on average more than 35 hours a week, are considered full time part year. Women who work between zero and 1750 hours, but who work on average less than 35 hours a week, are considered part time. ${ }^{8}$ Women who work zero hours or who have zero income are considered not working. Figure 1 shows that the percentage of women working full time and working full time part year declines over time while the percentage of women not working rises. The percentage of women working part time remains fairly constant.

Figure 2 plots the birth rate for women in the sample in a given year. The birth rate is simply the proportion of at risk women who give birth to a child in the year. The birth rate rises fairly dramatically in the early years, ${ }^{9}$ seems to reach a peak around 1990, and appears to decline slightly toward the end of the period.

Figures 3-5 present the labor force status for women in the years surrounding the birth of a child. Figure 3 presents these numbers for women who have one child by 1993, Figure 4 for women who have two children by 1993, and Figure 5 for women who have three children by 1993. In these figures 0 on the X-axis represents the year of the child's birth, the negative numbers represent the years prior to the birth and the positive numbers represent the years after the birth.

\footnotetext{
${ }^{6}$ Information on siblings comes from questions asked in the 1992 survey. We use infomation on the age of the children to calculate when the sibling first had the child. All data on years of schooling are truncated at 20 years in the NLSY79.

${ }^{7}$ All of our income numbers have been deflated using the CPI-U and are in 1979 dollars. We imputed income for a number of cases where it was missing. Our exact imputation procedure is described in the data appendix.

${ }^{8}$ We measure hours worked using information on hours worked per week avaliable in the NLSY79. We compute the average hours worked per week by summing the hours worked per week for the year and dividing by the number of weeks worked during the year. Due to problems with missing and invalid values we are forced to impute hours worked for a few women. We describe the imputation process in the data appendix.

${ }^{9}$ This is true partly by construction since women have zero children when they enter the panel.
} 
The top panel in Figure 4 shows this information around the birth of the first child while the bottom panel presents this information around the birth of the second child. In Figure 5 the top panel again is based on the birth of the first child and the bottom panel uses data from around the birth of the third child.

Figure 3 shows that, prior to the birth of their first child, almost 75 percent of women work full time, with the rest either working part time or full time part year. Very few women do not work at all. In the year of the birth the percentage of women working full time drops considerably, while there is a jump up in the percentage working full time part year as well as an increase in the percentage working part time or not working. After the birth of the child the percentage of women working full time part year returns to the pre-birth level while there is a continual increase in the percentage of women in all other labor market states. In every period full time contains the largest number of women.

Comparing the labor market behavior prior to the birth of their first child for women who have two children (Figure 4) or three children (Figure 5) we see a similar pattern to that seen in Figure 3; most women work full time prior to the birth of the first child and the rate remains fairly steady up to the year of the birth. However, comparing the percentage of women working full time across Figures 3-5 shows that women who have two or three children are 10 percentage points less likely to work full time prior to the birth of their first child than women who have only one child. While far from conclusive, this is evidence that expected future fertility affects pre-birth labor market behavior. ${ }^{10}$ One goal of our empirical analysis will be to see whether we can account for this difference using observable characteristics, such as education, race, or spouse's earnings, and unobserved heterogeneity.

Examining the labor market status across these three figures after the birth of the last child also reveals significant differences. In the bottom panels of Figures 4 and 5 we see that after the birth of the last child women are equally likely to work full time, part time, or to not work at all, with approximately 30 percent of women in each state. In Figure 3 we see that around 50 percent of women who have one child work full time in the periods following the birth with 20 percent of these women in the part-time or non-work state. This is evidence that the cost of having children does increase with the number of children. Another goal of the subsequent analysis will be to divide these costs into the direct and indirect components and to estimate the marginal cost of additional children.

These figures demonstrate that our four-state model of the labor market does a better job capturing the behavior of women, particularly around birth of a child. They also show that there are differences in labor market behavior that are related to subsequent fertility, suggesting that fertility is endogenous with respect to labor supply. In the next section we develop a statistical model that incorporates these findings.

\footnotetext{
${ }^{10}$ It could be that women who are less sucessful in the labor market have more children.
} 


\section{The empirical model}

The effect of children on women's labor supply has been the object of numerous applied and theoretical panel data econometric studies. Applied papers frequently assume implicitly or explicitly that, once they control for individual heterogeneity, children variables are exogenous. Hyslop (1999), for example, makes this assumption noting that there is no evidence against the exogeneity in settings which account for the dependence of sequential labor market decisions. On the other hand, theoretical panel data papers (Chamberlain, 1984; Arellano and Honore, 2001; Carrasco, 2001; Arellano and Carrasco 2003) have underscored the fact that exogeneity of children variables is a strong assumption even when controlling for measured characteristics since it requires that all variation in labor supply plans is explained or that labor supply plans have no effects on fertility decisions at any point in the life cycle.

In estimating models with continuous dependent variables, endogeneity has been addressed by employing instrumental-variables techniques based on the lack of correlation between future errors in first differences and lagged values of variables (Anderson and Hsiao, 1981; Holz-Eakin, Newey and Rosen, 1988; Arellano and Bond, 1991) and between first differences in predetermined variables and errors in levels (Arellano and Bover, 1995). In discrete choice models endogeneity has been modelled through correlation between regressors and an individual specific error component. Several methods of estimation are available. The conditional approach is based on defining a set of probabilities which do not depend on the individual-specific error component (Honore and Kiriazidou, 2000). Alternative approaches are based on specifying the distribution of the random effects, either completely as in Chamberlain (1984) or semi-parametrically as in Carrasco (2001) and Arellano and Carrasco (2003). While Chamberlain's approach requires strictly exogenous regressors, Carrasco (2001) and Arellano and Carrasco (2003) are applicable when regressors are predetermined. In a notable departure from the literature, Carrasco (2001) jointly estimates participation and fertility decisions by employing a switching probit model where the equations underlying the participation decision contain a semi-parametrically defined individual component.

In this paper we propose a model for labor market and fertility decisions that is more general than alternatives found in the literature. Labor market decisions and fertility decisions are generated by a sequential optimization process. At the beginning of each period an individual decides on the level of labor market involvement for the current period while simultaneously making a fertility decision. The level of labor market involvement is chosen from a set of four alternatives-full-time work (FT), full-time part-year work (FP), part-time work $(\mathrm{PT})$, non work(NW)-by comparing their associated value functions. In every time period fertility choices are driven by the comparison of value functions corresponding to having a child and not having a child, respectively. Let the value functions associated with each labor market state be denoted by $U_{i t}^{F T}$,

$U_{i t}^{F P}, U_{i t}^{P T}$, and $U_{i t}^{N W}$, respectively, and the difference of the relevant fertility value functions be $U_{i t}^{F}$. 
In reduced form, sequential labor market decisions are represented by a multinomial probit model with auto-correlated error terms while fertility decisions are represented by a probit model with state-dependence and autocorrelated error terms. ${ }^{11}$ Since the choice of a level of labor market involvement depends only on differences of value functions, we transform the model by considering only values relative to the nonwork state.

$$
\begin{aligned}
& U_{i t}^{1}=U_{i t}^{F T}-U_{i t}^{N W}=K_{i t} \alpha^{1}+X_{i t}^{L M} \beta^{1}+Z_{i t}^{1} \gamma+\sum_{m} K_{i t} \delta_{m l(i, m)}^{1}+u_{i t}^{1} \\
& U_{i t}^{2}=U_{i t}^{F P}-U_{i t}^{N W}=K_{i t} \alpha^{2}+X_{i t}^{L M} \beta^{2}+Z_{i t}^{2} \gamma+\sum_{m} K_{i t} \delta_{m l(i, m)}^{2}+u_{i t}^{2} \\
& U_{i t}^{3}=U_{i t}^{P T}-U_{i t}^{N W}=K_{i t} \alpha^{3}+X_{i t}^{L M} \beta^{3}+Z_{i t}^{3} \gamma+\sum_{m} K_{i t} \delta_{m l(i, m)}^{3}+u_{i t}^{3} \\
& U_{i t}^{F}=K_{i t} \alpha^{F}+X_{i t}^{F} \beta^{F}+\sum_{m} K_{i t} \delta_{m l(i, m)}^{F}+u_{i t}^{F}
\end{aligned}
$$

where the subscript $i$ indicates individuals, $i=1, \ldots, N$ and subscript $t$ indicates time periods, $t=1, \ldots, T_{i}$. The vectors $K_{i t}, X_{i t}^{L M}, X_{i t}^{F}$ contain variables describing the number of children and their age distribution, personal characteristics relevant to labor market decisions, and personal characteristics relevant to fertility decisions, respectively, while $Z_{i t}^{1}, Z_{i t}^{2}, Z_{i t}^{3}$ are expected wages in each of the alternative labor market states. In this model the $\alpha^{\prime} s$ and $\beta^{\prime} s$ are vectors of global (fixed effect) parameters.

The transformed latent variables define the labor market and fertility decisions the following way:

$$
\begin{aligned}
y_{i t}^{F T} & =1 \text { if } U_{i t}^{1}>U_{i t}^{2} \text { and } U_{i t}^{1}>U_{i t}^{3} \text { and } U_{i t}^{1}>0 ; 0 \text { otherwise } \\
y_{i t}^{F P} & =1 \text { if } U_{i t}^{2}>U_{i t}^{1} \text { and } U_{i t}^{2}>U_{i t}^{3} \text { and } U_{i t}^{2}>0 ; 0 \text { otherwise } \\
y_{i t}^{P T} & =1 \text { if } U_{i t}^{3}>U_{i t}^{1} \text { and } U_{i t}^{3}>U_{i t}^{2} \text { and } U_{i t}^{3}>0 ; 0 \text { otherwise } \\
y_{i t}^{N W} & =1 \text { if } U_{i t}^{1} \leq 0 \text { and } U_{i t}^{2} \leq 0 \text { and } U_{i t}^{3} \leq 0 ; 0 \text { otherwise }
\end{aligned}
$$

The fertility decision remains

$$
y_{i t}^{F}=1 \text { if } U_{i t}^{F}>0 ; 0 \text { otherwise }
$$

The vector of personal characteristics $X_{i t}^{L M}$ includes marital status, spouses wage, other income, region and urban/rural character of residence which are assumed to be exogenous. Determinants of fertility decisions, $X_{i t}^{F}$, are other income, region and urban/rural character of residence, as well as the number of siblings with children which captures family background characteristics

\footnotetext{
${ }^{11}$ By comparison, Carrasco (2001) specifies state-dependent participation decisions but static fertility decisions, while Vella and $\operatorname{Verbeek}(1998,1999)$ incorporate state dependence in the auxiliary (selection) equation but allow for dynamic effects in the main equation.
} 
potentially important to fertility decisions. The number of siblings with children is excluded from the participation equation while spouse's wage and the respondent's wage are excluded from the fertility equation. These exclusion restrictions, while not crucial, help identify the parameters of the model.

Following the suggestions of Nakamura and Nakamura (1992) we employ a somewhat richer specification to capture the effects of children than is typical. The vector $K_{i t}$ includes the number of children in three age categories (0-1, 2-4, 5 and older) and a constant term. Age is measured as age at last birthday. The construction of the children variables defines the dynamics of the fertility decisions and the relationship between fertility decisions and labor market decisions. Children variables, which are transformations of lagged values of fertility, describe the entire history of fertility decisions-how many children have been born and how far in the past-thus rendering current fertility and participation decisions dependent on the entire fertility history. This construction allows a more accurate representation of the relationship between fertility and participation decisions and generates a particular structure for the system of equations. Fertility decisions may result in the birth of twins. Had we defined fertility as the occurrence of a birth in the current period and included it in the participation equation we would have lost the information on the number of children born in a period, which is important in estimating the cost of children. Our use of the children variables to capture past fertility decisions is different from the structure typically used in the literature estimating dynamic panel data models where the contemporaneous dependent variables enter each equation. ${ }^{12}$

Personal characteristics and children variables vary over $i$ and $t$ but are constant across labor market states. Multinomial probit models such as this are frequently difficult to identify due to flat spots in the likelihood function. Therefore, we follow the suggestion of Geweke, et al. (1997) and include the variable $Z_{i t}$ in the model, which is the hourly wage of women in each labor market state. ${ }^{13}$ The variable $Z_{i t}$ varies over $i, t$, and labor market state, the coefficient on $Z_{i t}$ is constrained to be the same across states. When constructing $Z_{i t}$ we use the hourly wage for the labor market state the women is observed in and impute the hourly wage in the alternative states. ${ }^{14}$

We incorporate individual heterogeneity in the model by assuming that the constant term and the coefficients on the children variables in all equations differ across individuals. Specifically, we assume that there are $m=1, \ldots, M$ independent sources of heterogeneity affecting individuals' decisions. Each source of heterogeneity has $l_{m}$ levels. We use the following five sources of heterogeneity: individuals' time invariant personal characteristics (education, race) and

\footnotetext{
${ }^{12}$ For example, Carrasco (2001) includes the occurence of a birth in the participation equation. Vella and Verbeek (1998), who use panel data to estimate the union wage premium, include current union membership in the wage equation while simultaneously estimating the determinants of union status.

${ }^{13}$ See Geweke, et al. (1997) and Geweke and Keane (2001) for a further discussion of this issue and their proposed solution.

${ }^{14}$ We impute hourly wages in the alternative states using the coefficients from a standard wage regression estimated using observations on all women in the NLSY between 1979 and 1994.
} 
family background variables related to tastes for work and family (respondent's mother's labor market status and highest education of parents) as well as unobserved individual-level heterogeneity.

Each source of heterogeneity affects the variables $K_{i t}$. We assign to each individual in the data a level of heterogeneity for each source of heterogeneity $l(i, m)$. To level $l$ of heterogeneity source $m$ corresponds the vector of random coefficients $\delta_{m l}=\left[\delta_{m l}^{1^{\prime}}\left|\delta_{m l}^{2^{\prime}}\right| \delta_{m l}^{3^{\prime}} \mid \delta_{m l}^{F^{\prime}}\right]$ distributed normally, independently across the $l_{m}$ levels of heterogeneity of source $m, \delta_{m l} \sim M V N\left(0, D_{m}\right)$, and uncorrelated with the regressors $X_{i t}^{L M}, X_{i t}^{F}, Z_{i t}$ and the error terms $u_{i t}$. The random coefficients are assumed independent across sources of heterogeneity.

We associate the random effects corresponding to the constant in each equation to the individual propensity of being in a given labor market state and the propensity of having children, respectively. Similarly, the random coefficients affecting children variables reflect individual variations in the "cost of children" or in the effect of children on labor market and fertility decisions. The framework we use allows for a complex correlation structure both across equations (e.g. women with a higher propensity of having children could have a lower propensity to work full time and a higher propensity to work part time) and within equations (e.g. women with a higher propensity of working full time may face stronger negative effects of children on the likelihood of working full time). The use of alternative sources of heterogeneity allows the outcomes to be determined both by individual-level unobserved heterogeneity and by group-specific characteristics (education, race, family background).

Finally, we assume error terms are jointly normally distributed.

$$
u_{i t}=\left[u_{i t}^{1}\left|u_{i t}^{2}\right| u_{i t}^{3} \mid u_{i t}^{F}\right]^{\prime} \sim N(0, \Sigma) .
$$

Over time, error terms follow a $\operatorname{AR}(1)$ stationary process, $u_{i t}=R u_{i t-1}+$ $\varepsilon_{i t}$, where $\varepsilon_{i t}=\left[\varepsilon_{i t}^{1}\left|\varepsilon_{i t}^{2}\right| \varepsilon_{i t}^{3} \mid \varepsilon_{i t}^{F}\right]^{\prime}$ is distributed $\operatorname{IIDN}(0, \Psi), \Psi=I_{4}$, and it is uncorrelated with the random coefficients $\delta_{s k}$ and variables $X_{i t}^{L M}, X_{i t}^{F}, Z_{i t}$,

$$
R=\left[\begin{array}{cccc}
\rho_{1} & 0 & 0 & 0 \\
0 & \rho_{2} & 0 & 0 \\
0 & 0 & \rho_{3} & 0 \\
0 & 0 & 0 & \rho_{F}
\end{array}\right]
$$

Identification is achieved through the assumptions regarding the distribution of the random coefficients and exclusion restrictions.

The dynamic nature of both participation and fertility decisions requires assumptions regarding initial conditions. Given our specification, we need to know the distributions of children variables in the initial period and the distribution of the error terms. The selection of the sample ensures that initial conditions are identical across individuals-we choose the first year out of school as the first period in the sample and we include only women who marry and have children only after entering our sample.

To estimate the model, we employ Markov chain Monte Carlo techniques. The biggest advantage of this estimation framework is the data augmentation 
procedure it incorporates, which regards latent dependent variables as parameters. Conditional on the latent variables, the model becomes a tractable linear panel-data simultaneous-equation model with mixed effects, which can be generalized in a number of directions. The relationship between the latent variables and the observed discrete outcomes is easy to construct and therefore more complex relationships can be modeled. Our approach combines elements from several sources in the literature. Geweke et al. (1997) propose a Gibbs sampler algorithm for estimating a panel multinomial probit model where errors follow an AR(1) process. McCulloch and Rossi (1994) also use a Gibbs sampler to estimate a multiperiod multinomial probit model with random effects. The general random effects framework has been used for a long time in Bayesian hierarchical modeling of longitudinal data. In this paper we use the same approach as in Gilks et al. (1993). Also related, albeit in a continuous setting, is the paper by Chib and Greenberg (1995) on hierarchical SUR models with correlated errors. Finally, Markov chain Monte Carlo techniques for estimating multivariate probit models have been introduced by Chib and Greenberg (1998). We extend existing work by combining two discrete choice processes and jointly estimating the parameters of interest in both models. For the parameters of interest we choose proper but noninformative prior distributions. The estimation algorithm and the exact form of our assumptions concerning the prior distributions are presented in Appendix 1.

This approach differs from the existing literature in several respects. Our representation of the level of labor market involvement is richer than definitions previously used. The level of labor market involvement plays an important role in labor market dynamics. Studies using three-state models (full-time, part-time and nonwork) show that, conditional on initially working full-time, women tend to remain working throughout their lives (e.g., Blank, 1989 and 1994, using US data, and Giannelli, 1996, using German data). Part-time work represents a qualitatively different state: it is less persistent than full-time work and nonwork; for different categories of individuals, it represents an alternative to full-time work or to nonwork; it rarely becomes a stepping-stone into fullemployment for women who have been absent from the labor market. Motivated by the preliminary evidence on the different dynamics of full-time part-year and part-time employment, we augment the three-state model typically used by adding a fourth state, full-time part-year. Temporary work interruptions around birth are likely to be better reflected in the four state model.

The model we propose combines a flexible dynamic representation of the fertility process with an accurate representation of the number and age distribution of children in the household at a given time. In the spirit of Hotz and Miller (1988), we define the fertility variable as a dummy variable which takes value 1 if a child is conceived in a given year. ${ }^{15}$ The number of children and their age distribution enter both participation equations where they measure

\footnotetext{
${ }^{15}$ Hotz and Miller (1988), recognizing the importance of accurately describing the dynamics of fertility process, formulate a stochastic model of fertility in which contraceptive choices are regarded as fertility choices. Most other strudies equate fertility decision with the occurrence of a birth.
} 
the costs of having children and the fertility decisions, ensuring an appropriate dynamic representation of the fertility process. This specification is consistent with that used in studies measuring the effect of children on labor supply without addressing the endogeneity of fertility decisions, such as Shapiro and Mott (1994) who use age of the youngest child and the number of children and Hyslop (1999) who uses the number of children in three age categories, but is significantly more extensive than those used in studies mainly concerned with the endogeneity of fertility decisions, such as Arellano and Honore (2001) and Carrasco (2001) who use two dummy variables, one indicating the occurrence of a birth, the second indicating the presence of children ages 2-6 in the household.

The mixed-effect structure has not been previously used in studies measuring the effect of children on women's labor supply despite the importance of individual heterogeneity-both static and dynamic-in the relationship between fertility and labor market decisions. ${ }^{16}$ While the mixed-effect structure has been used in a variety of panel data models with continuous dependent variables (Kelejian, 1974; Balestra and Negasi,1992; Hsiao et al., 1992; Gilks et al, 1993; Pesaran and Smith, 1995) difficulty in implementation has precluded its use in classical panel data models with discrete dependent variables. In Bayesian econometrics, however, the advent of Markov chain Monte Carlo methods has made it possible to use general mixed effect models for a wide class of models.

\subsection{Results}

Estimation results are presented in tables 3, 4 and 5. Table 3 shows the posterior means and the posterior standard deviations (PSTD) for the coefficients. Table 4 shows the posterior means of the random effects for four sources of observable heterogeneity: education, race, respondent's mother's labor market status, and parent's education. Table 5 displays the posterior correlation matrix for the effect of unobserved individual heterogeneity on the constant and the children variables in the four equations.

There are a number of aspects of the coefficients in Table 3 that deserve attention. The coefficients on the three children variables show that the presence of children reduces the attractiveness of work. This effect is strongest for fulltime work (column 1) and weakest for part-time work (column 5). The effect also declines with the age of the child. Having young children increases the probability of having another child, but having children over five reduces fertility (column 7). Being married reduces the probability of working, but, similar to previous studies (e.g. Angrist and Evans, 1998), spouse's wage has very little

\footnotetext{
${ }^{16}$ Time invariant heterogeneity arising from different tastes for work and children can be modeled using correlated random effects in the participation and fertility equations. There is however evidence that individual heterogeneity is present beyond this static component. First, women differ not only with respect to their propensity to have children, but also with respect to timing of the first birth and the spacing of the subsequent births. Second, Browning (1992) points to evidence that labor market behavior around birth is heterogenous - the later in the pregnancy a women stops working, the sooner after birth she returns to work. Our preliminary evidence also shows significant difference in the dynamics of the level of labor market involvment around birth across women with different numbers of children.
} 
direct effect on the probability of working. Our estimates of $\rho$ show that work is persistent. However, we find that the degree of persistence varies by labor market state. Full-time part-year work is different from full-time and part-time both with respect to the effect of personal characteristics and its persistence (the estimated $\rho$ ). As expected full-time part-year is the least persistent state. Also, the $\operatorname{AR}(1)$ coefficient on fertility is negative, indicating that having a child in the previous year reduces the probability of having a child in the current year.

Random coefficient estimates in table 4 contain a large amount of information on the effect of personal characteristics on the latent variables driving the labor market and fertility decisions, the correlation between the labor market variables and fertility, and the relationship between the random coefficients affecting the constant and those affecting the children variables. ${ }^{17}$ The constant effects show that women with more than 15 years of schooling and no children are more likely to work full time (column 1), less likely to work part time (column 9), and less likely to have children (column 13) relative to women with twelve years of schooling or less. The constant effects also show that white women with no children are more likely to work full time or part time relative to black and Hispanic women, are less likely than Hispanic women to have children, but are slightly more likely than black women to have a child. At the same time the coefficients on the children variables show that having a child reduces the probability of working most severely for educated women and white women. This relationship is sharpest in the case of race where having a child of any age reduces the probability of working full time for white women but raises the probability for black and Hispanic women (columns 2-4). In addition, having a child increases the probability of working part time for white women while reducing the probability for black and Hispanic women (columns 10-12).

The constant term and the coefficients on the children variables are allowed to vary across individuals in all equations. Each individual is characterized by a vector of random coefficients which has a multivariate normal distribution. Table 5 shows the correlation matrix of the random coefficients. These correlation coefficients quantify the role of individual-level heterogeneity in participation and fertility decision. In discussing the results we refer to the random coefficients corresponding to the constant term as the propensity. For example, the propensity to work full time or the propensity to have children. The random coefficients corresponding to the children variables in the participation equations will be referred to as cost of having children, noting that a high cost means a low value of the corresponding random coefficient.

The first thing to note is that the propensities to work full time and full time part year are strongly correlated, the correlation coefficient is 0.9 . Both are less

\footnotetext{
${ }^{17}$ The interpretation of the random coefficients is analogous to that of the coefficients of a complete interaction between the children variables and each of the sources of heterogeneity in a classical regression setting. These coefficients describe how being in any category modifies the global effects of covariates. For example, having one child betwen ages 2 and 4 reduces the propensity of working by $-0.769+0.039=-0.730$ for someone with less than 12 years of education, by $-0.769-0.025=-0.791$ for someone with $13-15$ years of education, and by $-0.769-$ $0.013=-0.782$, for someone with 16 or more years of education.
} 
strongly correlated with the propensity to work part time (0.412 for full time and part time and 0.692 for full time part year and part time). This implies that full-time part-year employment is more similar to full-time employment than to part-time employment.

The diagonal block corresponding to the fertility decision describes the role of unobserved heterogeneity in the dynamics of fertility. High values of the random coefficients corresponding to the children variables indicate that the presence of children in the respective age category increases the probability of having another child. Therefore, they carry information about the spacing of births. The propensity to have children (the constant term) is strongly negatively correlated with the random coefficient for the number of children ages $0-1$ and $2-4$, the correlations are -0.820 and -0.876 , respectively, and positively correlated with the random effect corresponding to the number of children older than 5 . This shows that women with a higher propensity to have children are more likely to give birth at longer time intervals.

The correlations between the random coefficients corresponding to the constant terms in the participation equations and the random coefficients corresponding to the constant terms in the fertility equation vary from strongly negative (-0.599 for full time and Fertility) to positive ( 0.175 for part time and Fertility). This shows that women with stronger propensities for higher levels of labor market involvement have a lower propensity to have children.

The correlations between propensities corresponding to the participation equations and the coefficients of the children variables in the fertility equation describe the relationship between the level of labor market involvement and the spacing of births. For full time the correlations are $0.125,0.534$, and 0.925 for children in categories $0-1,2-4$, and older than 5 , respectively. These correlations indicate that for women who have a high propensity for full-time work, the presence of a young child in the household has a stronger positive effect on the probability of having another child than for those less likely to work full time, while the presence of an older child has a relatively stronger negative effect on the probability of having another child. By comparing these correlations with those corresponding to full time part year and part time we can see that, as the level of labor market involvement declines, the coefficients corresponding to young children (ages $0-1$ and 2-4) decline in absolute value while those corresponding to older children rise. This pattern indicates that women with a stronger propensity for a higher level of labor market involvement tend to give births at shorter time intervals.

The random coefficients corresponding to the children variables in the participation equations are positively correlated with the propensity of having children. This means that strong negative effects of children on the level of labor market involvement are associated with a lower propensity of having children. The coefficients corresponding to children ages $0-1$ and 2-4 in the participation equations are strongly negatively correlated with the effects of children in the same age categories on fertility. This implies that women who face high costs of children tend to give birth at shorter time intervals. 


\section{Pre- and Post-Birth Simulations}

Our analysis of the effect of children on a woman's labor market status has two goals. The first is to measure the effect of children on women's level of labor market involvement in the periods following birth, disentangle the direct and the indirect effects, and analyze how the direct and indirect effects vary with time, education, and race. The second is to assess the contributions of unobserved individual-level heterogeneity, education, and race to the observed differences in the pre-birth levels of labor market involvement.

We pursue these goals by constructing two simulation exercises that share several important characteristics. An individual is defined as a set of observable characteristics and a level of unobserved, individual-specific heterogeneity. We choose a baseline case with respect to personal characteristics (observed sources of heterogeneity) where we set the spouse's wage and other family income at their respective median levels. Effects of observable characteristics are calculated as differences from the baseline profile.

For every individual, labor market and fertility prospects are described by a joint probability distribution over the four labor market states and fertility decisions. Using the parameter estimates from our model, which are presented in Tables 3 and 4, we can construct the probability of any given combination of labor market and fertility histories for all individuals. ${ }^{18}$ The effect of a birth on labor market outcomes is inferred by comparing probability distributions over labor market states conditional on different fertility histories.

The large number of possible labor market and fertility histories forces us to simplify our analysis in several respects. First, we constrain our attention to the first eight years following entry into the labor market. Second, while we recognize that both the number of births and their timing may affect women's labor market behavior, we focus exclusively on the number of births. We measure the effects of one and two births by comparing fertility histories with zero, one, and two births, in which we impose a specific timing of the births. Finally, we limit ourselves to measuring the effects of fertility and labor market decisions only on the probability of working full time.

The basic questions addressed by the study of pre- and post-birth periods are fundamentally different. This difference has implications for the way we treat the two building blocks of the simulation exercises-births and unobserved heterogeneity. In the study of the post-birth period we measure the effects of one or two births on any given individual. For each individual we simulate the impact of zero, one, and two births on labor market outcomes. Our simulations attempt to identify the impact of the birth, per se, independent of expectations or preparations that might proceed conception. For example, for a couple that does not intend to have a child, a birth could result from a birth control failure. In the case of a couple attempting to conceive, the impact of a birth is relative to the case where the expected conception failed to occur. We then compute

\footnotetext{
${ }^{18}$ The probability of a complete history is the cumulative distribution function (CDF) of a multivariate normal distribution. To calculate the multivariate normal CDFs, we use the GHK smooth recursive simulator (Geweke, 1989; Hajivassiliou, 1990; and Keane, 1994).
} 
direct and indirect effects by comparing labor market outcomes conditional on different fertility histories. Unobserved heterogeneity is treated as a nuisance parameter. Global measures of the direct and indirect effects are constructed for each set of observed characteristics by integrating out unobserved heterogeneity.

However, most births are not due to uncontrollable variations such as birthcontrol accidents, but instead reflect choices on the part of individuals. In our study of the pre-birth period we assess whether differences in unobserved heterogeneity explain the observed correlation between the level of labor market involvement prior to birth and realized fertility. In this simulation exercise, births are no longer regarded as random events. Individuals with different levels of unobserved heterogeneity have different probabilities of choosing fertility histories with zero, one, or two births. For each individual, values of these probabilities, relative to those of the rest of the sample, reflect an individual's propensity of having fewer or more children. For each individual, we then simulate the impact of zero, one, and two births on labor market outcomes. The role of individual heterogeneity is assessed by comparing labor market outcomes, conditional on the same actual fertility history, across individuals with different propensities for having children.

\subsection{Post-Birth Simulation}

In our framework we can think of a child as having two effects on the labor market state of the mother. First, giving birth to a child reduces the level of labor market involvement during the period around the birth and, given the persistence in labor market states, will affect the level of labor market involvement in subsequent periods. Second, the new child becomes part of the household and, thereafter, directly affects labor market outcomes in subsequent years. To disentangle the indirect and direct effects we must be able to distinguish between the effect of a reduction in the level of labor market involvement on subsequent labor market outcomes and the effect of the presence of a child in the household.

The first step is to formalize what we mean by "reductions in the level of labor market involvement." For the post-birth exercise we assume that the years before birth are spent working full-time. Reductions in the level of labor market involvement are thought of as transitions from full-time work to full-time

part-year work, or part-time work, or non work. One can analyze the effect of one or more years spent in either of these alternative states on the probability of returning to full-time work in subsequent periods. Consider the case of a woman who has no births during the eight-year period we consider and works full time the first two years after entering the labor market. In the third year she can occupy any labor market state with probabilities given by the appropriate conditional distribution. Now, consider an identical woman that gives birth in the third period. The birth does not force the women into a given labor market state. Instead, it alters the distribution of labor market states in the surrounding periods. States with lower labor market involvement become more probable and the expected level of labor market involvement in the relevant period is, therefore, lower. The change in the probability distribution induced 
by birth and the associated reduction in the expected level of labor market involvement will be used to define the direct and indirect effects.

To disentangle the direct and indirect effects we can use the parameter estimates from our model to separately simulate the effect of spending time in any given alternative states and the effect of having a child in the household. In our simulations we consider the two possibilities. First, that the birth directly affects the distribution of labor market states only in the birth year (year 3 in our example)-what we refer to as a one-year interruption. Second, that the birth directly affects the distribution of labor market states in the birth year and the subsequent year (years 3 and 4 in our example)-what we refer to as a two-year interruption.

In order to formally define how we measure the direct and indirect effects consider first the case in which only one birth occurs in year 3 and the birth affects the distribution of labor market states only during the birth year. Call $S$ the set of all possible labor market states in a period and $s_{t}$ the labor market state in period $t$. Here $S$ consists of four possible values: full time $(f t)$, full time part year $(f p)$, part time $(p t)$ and non work $(n w)$. Then for our eight periods let $f_{j}\left(s_{1}, s_{2}, \ldots, s_{8}\right)$ denote the probability density for the entire range of labor market histories, where $j$ is a vector identifying whether or not a birth occurs in each year. In the current example, for simplicity, let $j=0$ identify the vector of 0 births in every period and $j=1$ identify the vector with one birth in year 3 and no births in all other year. Note that the probability density is conditional on a vector of observed characteristics and a level of individual-specific unobserved heterogeneity. We omit this conditioning to simplify notation.

To capture the change in distribution during the year of birth, we use conditional probabilities to rewrite $f_{j}\left(s_{1}, s_{2}, \ldots, s_{8}\right)$ as:

$$
\begin{gathered}
f_{j}\left(s_{1}, s_{2}, \ldots, s_{8}\right)=f_{j}\left(s_{1}, s_{2}\right) \times f_{j}\left(s_{3} \mid s_{1}, s_{2}\right) \times \\
f_{j}\left(s_{4}, \ldots, s_{8} \mid s_{1}, s_{2}, s_{3}\right), j=0,1 .
\end{gathered}
$$

In the current simulation we condition on $s_{1}=s_{2}=f t$. Given this, we can write the probability density of all possible labor market states after $s_{2}$ as:

$$
\begin{gathered}
f_{j}\left(s_{3}, \ldots, s_{8} \mid s_{1}=f t, s_{2}=f t\right)=f_{j}\left(s_{3} \mid s_{1}=f t, s_{2}=f t\right) \times \\
f_{j}\left(s_{4}, \ldots, s_{8} \mid s_{1}=f t, s_{2}=f t, s_{3}\right), j=0,1 .
\end{gathered}
$$

Further, the probability that an individual works full time at time $t$ is

$$
\begin{gathered}
f_{j}\left(s_{t}=f t \mid s_{1}=f t, s_{2}=f t\right)=\sum_{s_{3} \in S} f_{j}\left(s_{3} \mid s_{1}=f t, s_{2}=f t\right) \times \\
f_{j}\left(s_{t}=f t \mid s_{1}=f t, s_{2}=f t, s_{3}\right), j=0,1 .
\end{gathered}
$$

The total effect $\left(T E_{t}\right)$ of a child in period $t$ is then measured as:

$$
\begin{gathered}
T E_{t}=\sum_{s_{3} \in S}\left[f_{0}\left(s_{3} \mid s_{1}=f t, s_{2}=f t\right) \times f_{0}\left(s_{t}=f t \mid s_{1}=f t, s_{2}=f t, s_{3}\right)-\right. \\
\left.f_{1}\left(s_{3} \mid s_{1}=f t, s_{2}=f t\right) \times f_{1}\left(s_{t}=f t \mid s_{1}=f t, s_{2}=f t, s_{3}\right)\right], t=4, \ldots, 8 .
\end{gathered}
$$


We can then decompose equation (4) into a direct and indirect effect in the following manner. The indirect effect $\left(I E_{t}\right)$ in period $t$ will be:

$$
\begin{aligned}
I E_{t}= & \sum_{s_{3} \in S}\left[f_{0}\left(s_{3} \mid s_{1}=f t, s_{2}=f t\right)-f_{1}\left(s_{3} \mid s_{1}=f t, s_{2}=f t\right)\right] \\
& \times f_{0}\left(s_{t},=f t \mid s_{1}=f t, s_{2}=f t, s_{3}\right), t=4, \ldots, 8
\end{aligned}
$$

while the direct effect $\left(D E_{t}\right)$ in period $t$ will be:

$$
\begin{gathered}
D E_{t}=\sum_{s_{3} \in S} f_{1}\left(s_{3} \mid s_{1}=f t, s_{2}=f t\right) \times \\
{\left[f_{0}\left(s_{t}=f t \mid s_{1}=f t, s_{2}=f t, s_{3}\right)-f_{1}\left(s_{t}=f t \mid s_{1}=f t, s_{2}=f t, s_{3}\right)\right], t=4, \ldots, 8 .}
\end{gathered}
$$

To study the case in which only one birth occurs but it affects the distribution of labor market states during both the year of birth and the following year, we rewrite (3) as:

$$
\begin{gathered}
f_{j}\left(s_{t}=f t \mid s_{1}=f t, s_{2}=f t\right)=\sum_{s_{3} \in S} \sum_{s_{4} \in S} f_{j}\left(s_{3}, s_{4} \mid s_{1}=f t, s_{2}=f t\right) \\
\times f_{j}\left(s_{t}=f t \mid s_{1}=f t, s_{2}=f t, s_{3}, s_{4}\right), j=0,1 .
\end{gathered}
$$

Then the indirect and direct effects in period $t$ become:

$$
\begin{gathered}
I E_{t}=\sum_{s_{3} \in S} \sum_{s_{4} \in S}\left[f_{0}\left(s_{3}, s_{4} \mid s_{1}=f t, s_{2}=f t\right)-f_{1}\left(s_{3}, s_{4} \mid s_{1}=f t, s_{2}=f t\right)\right] \\
\times f_{0}\left(s_{t},=f t \mid s_{1}=f t, s_{2}=f t, s_{3}, s_{4}\right), t=5, \ldots, 8
\end{gathered}
$$

and

$$
\begin{gathered}
D E_{t}=\sum_{s_{3} \in S} \sum_{s_{4} \in S} f_{1}\left(s_{3}, s_{4} \mid s_{1}=f t, s_{2}=f t\right) \times\left[f_{0}\left(s_{t}=f t \mid s_{1}=f t, s_{2}=f t, s_{3}, s_{4}\right)\right. \\
\left.-f_{1}\left(s_{t},=f t \mid s_{1}=f t, s_{2}=f t, s_{3}, s_{4}\right)\right], t=5, \ldots, 8 .
\end{gathered}
$$

We use a similar strategy to measure the direct and indirect effects of a second birth taking place in, for example, year 5 . Here $j=2$ identifies the vector with one birth in year 3 , one birth in year 5 , and no births in all other periods. The direct and indirect effects are constructed by comparing the effects of one and two births on the probability of working full time. Assuming that the second birth affects the distribution over labor market states during the birth year only, the probability of working full time at time $t$ after the second birth can be written as

$$
\begin{gathered}
f_{j}\left(s_{t}=f t \mid s_{1}=f t, s_{2}=f t\right)=\sum_{s_{3} \in S} \sum_{s_{4} \in S} f_{j}\left(s_{3}, s_{4} \mid s_{1}=f t, s_{2}=f t\right) \times \\
{\left[\sum_{s_{5} \in S} f_{j}\left(s_{5} \mid s_{1}=f t, s_{2}=f t, s_{3}, s_{4}\right)\right.} \\
\left.\times f_{j}\left(s_{t}=f t \mid s_{1}=f t, s_{2}=f t, s_{3}, s_{4}, s_{5}\right)\right], j=1,2 .
\end{gathered}
$$


where $f_{1}\left(s_{3}, s_{4} \mid s_{1}=f t, s_{2}=f t\right)=f_{2}\left(s_{3}, s_{4} \mid s_{1}=f t, s_{2}=f t\right)$. The indirect and direct effects in period $t$ are now:

$$
\begin{gathered}
I E_{t}=\sum_{s_{3} \in S} \sum_{s_{4} \in S} f_{1}\left(s_{3}, s_{4} \mid s_{1}=f t, s_{2}=f t\right) \times \\
{\left[\sum_{s_{5} \in S}\left[f_{1}\left(s_{5}=c \mid s_{1}=f t, s_{2}=f t, s_{3}, s_{4}\right)-f_{2}\left(s_{5} \mid s_{1}=f t, s_{2}=f t, s_{3}, s_{4}\right)\right] \times\right.} \\
\left.f_{1}\left(s_{t} \mid s_{1}=f t, s_{2}=f t, s_{3}, s_{4}, s_{5}\right)\right], t=6, \ldots, 8
\end{gathered}
$$

and

$$
\begin{gathered}
D E_{t}=\sum_{s_{3} \in S} \sum_{s_{4} \in S}\left[f_{1}\left(s_{3}, s_{4} \mid s_{1}=f t, s_{2}=f t\right) \times\right. \\
\left.\sum_{s_{5} \in S}\left[f_{2}\left(s_{5} \mid s_{1}=f t, s_{2}=f t, s_{3}, s_{4}\right) \times f_{1}\left(s_{t} \mid s_{1}=f t, s_{2}=f t, s_{3}, s_{4}, s_{5}\right)\right]\right]- \\
\sum_{s_{3} \in S} \sum_{s_{4} \in S}\left[f_{2}\left(s_{3}, s_{4} \mid s_{1}=f t, s_{2}=f t\right) \times\right. \\
\sum_{s_{5} \in S}\left[f_{2}\left(s_{5} \mid s_{1}=f t, s_{2}=f t, s_{3}, s_{4}\right)\right. \\
\left.\times f_{2}\left(s_{t} \mid s_{1}=f t, s_{2}=f t, s_{3}, s_{4}, s_{5}\right)\right], t=6, \ldots, 8 .
\end{gathered}
$$

Our post-birth simulation has several distinct components. We assume that the person marries in the second year and works full time in the first two years. Three alternative fertility histories are used: no birth occurs during the eight years, one child is born during the third year and no subsequent birth occurs, one child is born in the third year and a second child is born in the fifth year. We compare a set of eight labor market decisions made during the year of birth and the subsequent years.

The effects of education and race are measured as deviations from our baseline case of personal characteristics. For all types of education and race the results are integrated over levels of unobserved individual heterogeneity. To incorporate individual heterogeneity we draw a random sub-sample of 100 individuals and use the posterior means of their respective individual effects in calculating the probability of each event of interest. The complete set of simulation scenarios are presented in Table 6 . The entries in the table define the events we condition on. For all scenarios we compute the conditional probability of working full time in each of the subsequent five years.

To provide a sense of what is being captured in our simulations Tables 7 and 8 present the probability of working full time conditional on working in another labor market state for one or two years and conditional on having or not having a child in year 3 for selected categories of individuals. Table 7 compares white women with mothers who did not work full time and one parent with a college education, across levels of own education. Table 8 compares women with 12 or fewer years of education, whose mothers did not work full time and one parent is college educated, across race. 
Column 1 in table 7 shows the probability of working full time conditional on not having a child and having worked full time in year three. The probability of working full time in year four is higher for women with more education (0.664 for 12 or fewer years of education, 0.750 for $13-15$ years of education, and 0.791 for 16 or more years of education). In the subsequent years the probability of working full-time declines for all levels of education. The decline is significantly faster for lower levels of education-in five years the full time probability declines by 18 percentage points for women with 12 or less years of education compared to 11 percentage points for women with 16 or more years of education. These results show that the persistence of full-time work increases with the level of education.

By comparing the "No child" columns for one-year spells spent in each of the four labor market states we can infer the effect of a reduction in the level of labor market involvement on the probability of working full time in subsequent years. For all labor market states one year spent in a different state reduces the probability of working full time in the following years. The probability of working full time in the fourth year is lower after being in states associated with lower levels of labor market involvement. For example, for women with 12 or fewer years of education the probability of working full time in the fourth year is 0.664 following a year of full-time work, 0.404 following a year of full-time part-year work, 0.338 following a year of part-time work, and 0.329 following a year of non work. For all states the effect of spending a year in another state decreases over time but remains large even five years after the interruption. The probability of returning to full-time work has different dynamics across states-it is slower after a year in the full-time part-year state. The comparison of the columns corresponding to one and two-year interruptions for each state, shows that longer spells spent in alternative states further lowers the probability of returning to full-time work.

The effect of one child on the probability of working full time after birth is measured by the difference between the "No child" and "Child" columns for each alternative state and each length of time spent in the alternative state. The first thing to note is that presence of children in the household significantly reduces the probability of working full time after birth. The probability of working full time is lower in the "Child" column regardless of the labor market state during the birth year. Differences between the probabilities in the two columns, however, differ across labor market states during the birth year indicating that children have a larger effect on those with a stronger labor market attachment. For women with 12 or fewer years of education, the presence of a child in the household reduces the probability of working full time in the fourth year by 17.7 percentage points (from 0.404 to 0.227 ) for those who spent the birth year working full time part year, by 14.9 percentage points (from 0.338 to 0.189 ) for those who spent the birth year working part time, and by 14.2 percentage points (from 0.329 to 0.187 ) for those who did not work at all during the birth year.

The effect of a child declines with the age of the child. A child born in the third year changes age categories in year 5, from 0-1 to 2-4, and in year 8 from $2-4$ to 5 and older. For all alternative states and for all levels of education year 
8 corresponds to the largest decline in the effect of a child on the probability of working full time. For example, for women in the lowest educational category who spent the year of birth working full time part year, the effect of a child declines from 17.8 percentage points in year 7 to 13.3 percentage points in year 8. The decline is larger for more educated women. Between year 7 and year 8 the effect of a child declines by roughly 8 percentage points for women with 13 or more years of education.

Women with lower levels of education are less likely to return to full-time jobs. After spending the birth year working full time part year, the probability of working full time rises to 0.322 five years after birth for women with 12 or less years of education but is 0.535 for women with 16 or more years of education. Also, maintaining some level of labor market involvement helps individuals return to full-time jobs faster. Five years after birth the labor market state occupied at birth makes no significant difference on the probability of working full time. In the years immediately following birth, however, women who maintained a higher level of labor market involvement have a higher probability of working full time. For all levels of education women who work full time part year during birth year are more likely to work full time immediately after birth than those who spent the birth year in part-time work or not working (in the first year after birth, 0.227 compared to 0.189 and 0.187 for women with 12 or less years of education, 0.313 compared with 0.259 and 0.260 for those with 13-15 years of education, and 0.364 compared with 0.298 and 0.301 for those with 16 or more years of education).

The same patterns can be seen in Table 8. Both time spent in alternative states and the presence of children reduce the probability of returning to full-time jobs. Race has an interesting effect on labor market outcomes. The full-time state is more persistent for white women. The effect of having children, however, is more pronounced for white women. Put differently, black and Hispanic women are less likely to work full time but having a child has a smaller negative effect on the probability of working full time.

Table 9 presents the direct and indirect effects of having one and two children separately by education and race. For the first birth we measure the effect where the birth affects the distribution of labor market states for one year (One-year interruption) and for two years (Two-year interruption). Focusing on the oneyear interruption effects for the first birth (columns 1 and 2) we see that the direct effect is larger than the indirect effect and that the direct effect declines as the child moves into a different age category (between years 7 and 8). The indirect effect also declines quite rapidly over time. The indirect effect falls by almost one-half between years 4 and 5 and is almost zero by year 8 . The rapid decline in the indirect effect shows that women overcome the effect of lost human capital very quickly and seem to suffer no long term effect from dropping out of the labor market for one year. In Appendix Table 1 we present estimates of the direct and indirect effects constructed using estimation results from the model without controlling for individual heterogeneity. Here, particularly for less educated women and for black and Hispanic women, the decline in the indirect effect over time is much slower. The decline in the indirect effect seen 
in Table 9 is not simply due to differences in human capital investment or differences in unmeasured heterogeneity.

Comparing across education groups we see that both the direct and indirect effect decline with education, with the sharpest decline in the indirect effect. Comparing white, black, and Hispanic women with twelve or fewer years of education we see that black and Hispanic women have smaller direct and indirect effects. This is not surprising given the results in Table 4 and may indicate that black and Hispanic women have better access to informal childcare.

Comparing across the columns we see that the indirect effect is larger when we allow the effect of the birth to impact the distribution of labor market states for two years, but the direct effect is smaller (columns 3 and 4). Comparing the direct and indirect effect of the first child with the marginal direct and indirect effect of the second child we see that the effect of having a second child is smaller that the effect of the first child. This suggests that studies such as Carrasco (2001), Angrist and Evans (1998), and Rosenzweig and Wolpin (1980) which all use exogenous variation in the birth of the second or third child to measure the effects of children, will underestimate the effect of having one child on a women's labor supply. Focusing on the effects of the second child, we also see that both the direct and indirect effects are increasing with education. For more educated women the relative effect of having a second child is larger than for the first child.

\subsection{Pre-Birth Simulation}

Our pre-birth simulation scenarios are slightly different than our post-birth scenarios in order to maximize the number of pre-birth years. We again construct labor market and fertility histories for eight periods following entry into the labor market. Now, however, we assume that women get married in the third year. We drop the assumption that women work full time in years 1 and 2 . We estimate the probability that a women has zero, one or two children and examine three alternative realized fertility histories: no child born in any year, one child born in the fifth year and no subsequent birth, one child born in the fifth year and a second child born in the seventh year. The pre-birth scenarios are presented in Table 10.

We choose the same baseline case with respect to personal characteristics that we used in the post-birth simulations. We then add to them the race and education effects, giving us a total of five different profiles. We use the same 100 randomly selected levels of heterogeneity used in the post-birth simulation and attach them to each of the five profiles (giving us 500 observations). For each level of unobserved heterogeneity we compute the joint probability of all possible labor market and fertility histories over the eight periods. Given these joint probabilities, for each level of heterogeneity we can compute the probability of having no children in any year, one child in year five, and one child in year five and one child in year seven, along with the probability of all possible labor market histories conditional on the specific fertility history. Using principal components analysis we then divide the 100 levels of heterogeneity according 
to their respective probabilities for the three fertility histories into three equal size groups: those likely to have zero children, those likely to have one child, and those likely to have two children. We then group women by the number of children they actually have and examine the effect of differences in expected fertility by plotting the probability of working full time averaged across the levels of heterogeneity within each level of expected fertility. The results are presented in Figures 6-10.

In Figures 6-8 we plot the average probability that a women works full time with the lines in the graphs corresponding to the number of children a women is likely to have. The panels in the graph vary by the number of children born. ${ }^{19}$ Figure 6 refers to women with low education (12 years or fewer), Figure 7 refers to women with medium education (13 to15 years) and Figure 8 refers to highly educated women (16 or more years). These figures are all based on white women.

These figures show that our statistical model captures much of the behavior seen in the raw data (Figures 3-5). The probability that a women works full time varies by the likely number of children and declines with the actual birth of a child. These figures imply that the differences in labor market status prior to the birth of the first child is primarily a function of unobserved heterogeneity. More educated women are more likely to work full time. However, regardless of education level, women who are likely to have two children are much less likely to work full time immediately after entering the labor market than women who are likely to have zero children, and the differences in probabilities are relatively constant across education level.

This point can be seen clearly in Figure 9. Here we graph the probability of working full time for white women who have two children. The lines in the graphs refer to different levels of education, while the panels differ by the likely number of children. It is again the case that while more education is associated with a higher probability of working full time, women who are likely to have more children are less likely to work full time regardless of education level, and the distance between the lines is similar across the three panels.

Figure 10 is similar to Figure 9 except now the lines in the graphs vary by race. Here we see that while there are fairly small differences across race in the probability of working full time, the effect of children does vary by race. Regardless of the number of children that they are likely to have, immediately after entering the market white women are more likely to work full time than black or Hispanic women. However, after the birth of the second child white women are the least likely to work full time, with black women being the most likely to work full time.

\footnotetext{
${ }^{19}$ Since women only have children in years 5 and 7 the movement in all of the lines between years 1 and 4 will be identical in all of the panels and the movements in the lines bettwen years 1-6 will be the same in panels B and $\mathrm{C}$.
} 


\section{Conclusions}

Three basic mechanisms are behind the statistical relationship between fertility decisions and labor force participation decisions. First the direct effect where an increase in the value of home time (child-care) reduces the labor market effort leading to a temporary drop in post-birth labor force participation. Second, the indirect effect where the time spent out of the labor market while on maternity leave alters women's participation experience and, thus, indirectly affects future participation behavior. Third, unobserved heterogeneity where differences in tastes for work and family structure may induce a correlation between participation and fertility decisions throughout the lifetime. They may further induce differences in pre-market human capital investments and, thus, affect labor market outcomes.

In this paper we propose a model that disentangles these three mechanisms and evaluates their relative importance. Sequential participation and fertility decisions are jointly modeled. Participation decisions on a four-state spaceemployed full time, employed full time part year, employed part time, not employed-and dichotomous fertility decisions are represented by a multivariate probit model with a general correlation structure. The model allows for a high degree of flexibility in modeling the correlation between labor force participation and fertility decisions and the dependence of sequential decisions. We estimate this model using data from the 1979 National Longitudinal Survey of Youth. The estimation is performed using Markov chain Monte Carlo methods.

We find that children have a strong effect on women's labor market behavior in the post-birth period and that differences in expected fertility affect women's labor market behavior in the pre-birth period. Consistent with the relevant theoretical models, we find that the direct effect of children declines as children age. The indirect effect also declines quite rapidly over time and this decline is independent of differences in education and unobserved heterogeneity. The loss of human capital as a result of having a child does not appear to have a long term impact on a women's labor market behavior. We also find that the marginal effect of a second child is smaller than the effect of the first child implying that previous estimates of the effect of children on women's labor supply, which are based on estimates exploiting exogenous variation in the second or third child, may understate the effect of the first child on a women's labor supply. Both the direct and indirect effects are smaller for black and Hispanic women. The direct and indirect effects of the first child decline with education level, while the opposite is true for the second child. The second child has a relatively larger impact on more educated women than the first. Finally, we find that women likely to have fewer children are more likely to work full time immediately after entering the labor market. Fertility behavior is associated with prior labor market decisions; expectations about future fertility affects current labor market decisions. These differences appear largely due to individual heterogeneity and are not due to differences in investment in human capital. 


\section{Appendix.}

\subsection{Estimation algorithm}

To estimate the model, we employ Markov chain Monte Carlo techniques. Our approach combines elements from several sources in the literature. Geweke et al. (1997) propose a Gibbs sampler algorithm for estimating a panel MNP model where errors follow an AR(1) process. McCulloch and Rossi (1994) also use a Gibbs sampler to estimate a multiperiod multinomial probit model with random effects. The general random effects framework has been used for a long time in Bayesian hierarchical modeling of longitudinal data. In this paper we use the same approach as in Gilks et al. (1993). Also related, albeit in a continuous setting, is the paper by Chib and Greenberg (1995) on hierarchical SUR models with correlated errors. Finally, MCMC techniques for estimating multivariate probit models have been introduced by Chib and Greenberg (1998). We extend existing work by combining two discrete choice processes and jointly estimating the parameters of interest in both models.

The data set is an unbalanced panel, with $N$ individuals $i=1, . ., N$, each individual $i$ is observed for $T_{i}$ periods. The total number of observations is $d f=\sum_{i=1}^{N} T_{i}$. Let $W_{i t}^{L M}=\left[K_{i t} \mid X_{i t}^{L M}\right], W_{i t}^{F}=\left[K_{i t} \mid X_{i t}^{F}\right]$, and define the block diagonal matrices

$$
\tilde{W}_{i t}=\left[\begin{array}{cccc}
W_{i t}^{L M} & 0 & 0 & 0 \\
0 & W_{i t}^{L M} & 0 & 0 \\
0 & 0 & W_{i t}^{L M} & 0 \\
0 & 0 & 0 & W_{i t}^{F}
\end{array}\right], \tilde{K}_{i t}=\left[\begin{array}{cccc}
K_{i t} & 0 & 0 & 0 \\
0 & K_{i t} & 0 & 0 \\
0 & 0 & K_{i t} & 0 \\
0 & 0 & 0 & K_{i t}
\end{array}\right]
$$

The conforming matrix of parameters is $\tilde{\beta}=\left[\alpha^{1 \prime}\left|\beta^{1 \prime}\right| \alpha^{2 \prime}\left|\beta^{2 \prime}\right| \alpha^{3 \prime}\left|\beta^{3 \prime}\right| \alpha^{F^{\prime}} \mid \beta^{F^{\prime}}\right]^{\prime}$. Define $U_{i t}=\left[U_{i t}^{1}\left|U_{i t}^{2}\right| U_{i t}^{3} \mid U_{i t}^{F}\right]^{\prime}, Z_{i t}=\left[Z_{i t}^{1}\left|Z_{i t}^{2}\right| Z_{i t}^{3} \mid 0\right]^{\prime}$. Using this notation the model becomes

$$
U_{i t}=\tilde{W}_{i t} \tilde{\beta}+Z_{i t} \gamma+\sum_{m} \tilde{K}_{i t} \delta_{m l(i, m)}+u_{i t}
$$

Define $U_{i 0}=u_{i 0}, \tilde{K}_{i 0}=[0], \tilde{W}_{i 0}=[0], Z_{i 0}=[0]$. Finally, let $\dot{U}_{i t}=U_{i t}-$ $R U_{i t-1} ; \dot{\tilde{W}}_{i t}=\tilde{W}_{i t}-R \tilde{W}_{i t-1} ; \tilde{K}_{i t}=\tilde{K}_{i t}-R \tilde{K}_{i t-1} ; \dot{Z}_{i t}=Z_{i t}-R Z_{i t-1}$.

To describe the sequence of labor market and fertility decisions, define $d_{i t}^{L M}=\left[d_{i t}^{1}, d_{i t}^{2}, d_{i t}^{3}, d_{i t}^{0}\right]=\left[y_{i t}^{F T}, y_{i t}^{F P}, y_{i t}^{P T}, y_{i t}^{N W}\right], d_{i t}^{F}=y_{i t}^{F}, d_{i t}=\left[d_{i t}^{L M}, d_{i t}^{F}\right], d_{i}=$ $\left[d_{i 1}, \ldots, d_{i T}\right]$.

The posterior kernel is given by the product of a multivariate normal kernel, the kernel of the unconditional distribution of the pre-sample error terms, the prior distributions of the parameters, and an indicator function controlling the ordering and the signs of the latent variables.

- The kernel of the joint normal distribution is: 


$$
|\Psi|^{-\frac{d f}{2}} \exp \left\{-\frac{1}{2} \sum_{i=1}^{N} \sum_{t=1}^{T_{i}}\left(u_{i t}-R u_{i, t-1}\right)^{\prime} \Psi^{-1}\left(u_{i t}-R u_{i, t-1}\right)\right\}
$$

where $u_{i t}=U_{i t}-\tilde{W}_{i t} \tilde{\beta}-Z_{i t} \gamma-\sum_{m} \tilde{K}_{i t} \delta_{m i}$

- The kernel of the unconditional distribution of the pre-sample error:

$$
\left|V_{0}(R, \Psi)\right|^{-\frac{N}{2}} \exp \left\{-\frac{1}{2} \sum_{i=1}^{N} u_{i 0}^{\prime}\left[V_{0}(R, \Psi)\right]^{-1} u_{i 0}\right\}
$$

where $\left[V_{0}(R, \Psi)\right]_{j k}=\frac{\psi_{j k}}{\rho_{j} \rho_{k}}$

- The indicator function for consistency and signs of U's:

$$
\prod_{i=1}^{N} \prod_{t=1}^{T_{i}} H\left(U_{i t}, d_{i t}\right)
$$

- Prior distributions

a. $\beta_{j} \sim N\left(\beta_{j 0}, B_{j 0}\right), j \in(1,2,3, F)$

b. $\gamma \sim N\left(\gamma^{0}, \Gamma_{0}\right)$

c. $\rho_{j} \sim T N\left(\rho_{j}^{0}, \sigma_{\rho_{j}^{0}}\right), j \in(1,2,3, F)$

d. $D_{m}^{-1} \sim W\left(b_{m}, B_{m}\right)$

The prior distribution for $\beta$ is multivariate normal with mean 0 and a variance matrix of 100 times the identity matrix, the prior distribution for $\gamma$ is univariate normal with mean 0 and variance 100, the prior distribution for $\rho$ is truncated normal with mean 0.5 and variance 0.25 , the prior distribution for the precision matrix $D_{m}^{-1}$ is Wishart with parameters $b_{m}=3, B_{m}=0.01 * I$, where $I$ is an identity matrix with appropriate dimension.

A seven-step Gibbs sampling algorithm is employed to construct draws from the posterior distribution.

- Step 1. Draw $U_{i t}\left(i=1, \ldots, N, t=1, \ldots, T_{i}\right)$

$\left[U_{i t} \mid \tilde{\beta}, \gamma, \delta_{s k(i, s)}, D_{s}, R, u_{i 0}\right]$ is a truncated multivariate normal distribution with mean $\left[\begin{array}{c}\mu_{i 1}+R u_{i 0} \\ \ldots \\ \mu_{i T}+R^{T} u_{i 0}\end{array}\right]$ and variance $G\left(I_{T} \otimes \Psi\right) G^{\prime}$ where $\mu_{i t}=\tilde{W}_{i t} \tilde{\beta}+$ $Z_{i t} \gamma+\sum_{s} \tilde{K}_{i t} \delta_{s k(i, s)}$ and

$$
G=\left[\begin{array}{cccccc}
I_{4} & 0 & 0 & \ldots & 0 & 0 \\
R & I_{4} & 0 & \ldots & 0 & 0 \\
\ldots & \ldots & \ldots & \cdots & \ldots & \ldots \\
R^{T-1} & R^{T-2} & R^{T-3} & & R & I_{4}
\end{array}\right]
$$


To draw from a truncated normal distribution, we used the method proposed by Geweke (1991).

- Step 2. Draw $u_{i 0}(i=1, \ldots, N)$.

The conditional distribution $\left[u_{i 0} \mid U_{i t}, \tilde{\beta}, \gamma, \delta_{s k(i, s)}, D_{s}, R\right]$ is only a function of $u_{i 1}, R$, and $\Psi$.

$$
u_{i 0} \sim N\left[C u_{i 1}, V_{0}(R, \Psi)-C V_{0}(R, \Psi) C^{\prime}\right]
$$

where $C=\left[V_{0}(R, \Psi)\right] R\left[V_{0}(R, \Psi)\right]^{-1}$

- Step 3. Draw $\rho$. The conditional distribution distribution $\left[\rho \mid U_{i t}, \tilde{\beta}, \gamma, \delta_{s k(i, s)}, D_{s}, u_{i 0}\right]$ is

$$
N\left[H_{\rho}\left(\nu_{\rho}+V_{\rho}^{-1} \rho^{0}\right),\left(H_{\rho}+V_{\rho}^{-1}\right)^{-1}\right]
$$

truncated to the hypercube dictated by stationarity, where

$$
\left.\begin{array}{rl}
H_{\rho} & =\left[\begin{array}{cccc}
\psi^{11} \sum_{i=1}^{N} \sum_{t=1}^{T_{i}}\left(u_{i t-1}^{1}\right)^{2} & \ldots & \psi^{13} \sum_{i=1}^{N} \sum_{t=1}^{T_{i}} u_{i t-1}^{1} u_{i t-1}^{3} & \psi^{1 F} \sum_{i=1}^{N} \sum_{t=1}^{T_{i}} u_{i t-1}^{1} u_{i t-1}^{F} \\
\psi^{13} \sum_{i=1}^{N} \sum_{t=1}^{T_{i}} u_{i t-1}^{1} u_{i t-1}^{3} & \ldots & \psi^{33} \sum_{i=1}^{N} \sum_{t=1}^{T_{i}}\left(u_{i t-1}^{3}\right)^{2} & \psi^{3 F} \sum_{i=1}^{N} \sum_{t=1}^{T_{i}} u_{i t-1}^{3} u_{i t-1}^{F} \\
\psi^{F 1} \sum_{i=1}^{N} \sum_{t=1}^{T_{i}} u_{i t-1}^{F} u_{i t-1}^{1} & \psi^{F 3} \sum_{i=1}^{N} \sum_{t=1}^{T_{i}} u_{i t-1}^{F} u_{i t-1}^{3} & \psi^{F F} \sum_{i=1}^{N} \sum_{t=1}^{T_{i}}\left(u_{i t-1}^{F}\right)^{2}
\end{array}\right] \\
\nu_{\rho}=\left[\begin{array}{c}
\sum_{j} \psi^{1 j} \sum_{i=1}^{N} \sum_{t=1}^{T_{i}} u_{i t-1}^{1} u_{i t}^{j} \\
\sum_{j} \psi^{3 j} \sum_{i=1}^{N} \sum_{t=1}^{T_{i}} u_{i t-1}^{1} u_{i t}^{j} \\
\sum_{j} \psi^{F j} \sum_{i=1}^{N} \sum_{t=1}^{T_{i}} u_{i t-1}^{F} u_{i t}^{j}
\end{array}\right], V_{\rho}=\operatorname{diag}\left(\sigma_{\left.\rho_{1}^{0}, \sigma_{\rho_{1}^{0}}, \sigma_{\rho_{3}^{0}}, \sigma_{\rho_{F}^{0}}\right)}\right.
\end{array}\right]
$$

Due to the truncation, an acceptance step is necessary. Draws are rejected if $\left|\rho_{j}\right| \geq 1$ for any $j$, then accepted with probability

$$
\left|V_{0}(R, \Psi)\right|^{-\frac{N}{2}} \exp \left\{-\frac{1}{2} \operatorname{tr} S_{u_{0}} V_{0}(R, \Psi)^{-1}\right\} \div\left|\frac{1}{N} S_{u_{0}}\right|^{-\frac{N}{2}} \exp \left(-\frac{N L}{2}\right)
$$

where $S_{u_{0}}=\sum_{i=1}^{N} u_{i 0} u_{i 0}^{\prime}$ 
- Step 4. Draw $\tilde{\beta}_{j}, j=1,2,3, F$. Conditional distribution $\left[\tilde{\beta}_{j} \mid U_{i t}, \gamma, \delta_{s k(i, s)}, D_{s}, R, u_{i 0}\right]$ is a multivariate normal $\tilde{\beta}_{j} \sim N\left[b_{j}, B_{j}\right]$

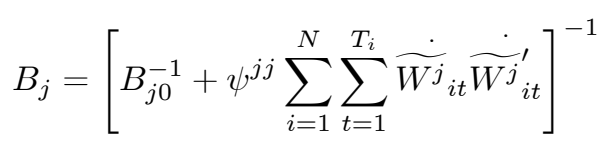

and mean

$$
b_{j}=B_{j}\left(B_{j 0}^{-1} \beta_{j 0}+\sum_{l} \psi^{j l} \sum_{i=1}^{N} \sum_{t=1}^{T_{i}} \stackrel{\dot{W^{j}}}{i t} w_{i t}^{l(j)^{\prime}}\right)
$$

where $w_{i t}^{l(j)}=\dot{U_{i t}^{l}}-\dot{\widetilde{W}}_{i t}^{l} \tilde{\beta}_{l}-Z_{i t}^{l} \gamma-\sum_{m} \tilde{K}_{i t} \delta_{m l(i, m)}$, for $l \neq j$ and $w_{i t}^{j(j)}=$ $U_{i t}^{j}-Z_{i t}^{j} \gamma-\sum_{m} \tilde{K}_{i t} \delta_{m l(i, m)}$

- Step 5. Draw $\gamma$.Conditional distribution $\left[\gamma \mid U_{i t}, \tilde{\beta}, \delta_{s k(i, s)}, D_{s}, R, u_{i 0}\right]$ is normal $\gamma \sim N[g, \Gamma]$

where the variance is

$$
\Gamma=\left[\Gamma_{0}^{-1}+\sum_{i=1}^{N} \sum_{t=1}^{T_{i}} \sum_{l} \sum_{j} \psi^{j l} \dot{Z}_{i t}^{j} \dot{Z}_{i t}^{l^{\prime}}\right]^{-1}
$$

and the mean is

$g=\Gamma\left(\Gamma_{0}^{-1} \gamma_{0}+\sum_{i=1}^{N} \sum_{t=1}^{T_{i}} \sum_{l} \sum_{j} \psi^{j l} \dot{Z_{i t}^{j}}\left(\dot{U_{i t}^{l}}-\dot{W_{i t}^{l}} \widetilde{\beta}_{l}-\sum_{m} K_{i t} \delta_{m l(i, m)}^{l}\right)\right)$

where $j, l=1,2,3, F$.

- Step 6. Draw $\delta_{m l}$ for each source of heterogeneity. Conditional distributions $\left[\delta_{m l} \mid U_{i t}, \tilde{\beta}, \gamma, D_{s}, R, u_{i 0}\right]$ are multivariate normal

$\left[\delta_{m l} \mid.\right]=N\left(D_{m} \sum_{i: l(i, m)=k} \sum_{t=1}^{T} \tilde{K}_{i t} \Psi^{-1} e_{m i t}, D_{m}\right)$

where

$D_{m}=\left[\Omega_{m}^{-1}+\sum_{i: l(i, m)=k} \sum_{t=1}^{T} \tilde{K}_{i t} \Psi^{-1} \tilde{K}_{i t}^{\prime}\right]^{-1}$

and 


$$
e_{m i t}=U_{i t}-\tilde{W}_{i t} \tilde{\beta}-Z_{i t} \gamma-\sum_{g: g \neq m} \tilde{K}_{i t} \delta_{g l(i, g)} . \text { Here, } \sum_{i: l(i, m)=k} \text { means sum for }
$$

all individuals observations $i$ for whom factor $m$ is at level $k$ and $\sum_{g: g \neq m}$ means sum for all factors except $m$.

- Step 7. Draw $D_{m}^{-1}$ for each source of heterogeneity. Conditional distributions $\left[D_{m}^{-1} \mid U_{i t}, \tilde{\beta}, \gamma, \delta_{m l}, R, u_{i 0}\right]$ are Wishart.

$D_{m}^{-1} \sim W\left(b_{m}+k_{m}, B_{m}+\sum_{l=1}^{l_{m}} \delta_{m l} \delta_{m l}^{\prime}\right)$

Convergence is assessed using the method proposed by Gelman and Rubin (1992) with the modified correction factor proposed by Brooks and Gelman (1998). One preliminary run of 14000 iterations, with OLS coefficients as starting values, was used to construct starting values for four independent chains. The starting values were extreme values chosen form the posterior distribution of the coefficients. The four independent chains, each with 15000 iterations were used to compute the scale reduction factor. Appendix Table 2 shows the scale reduction factors for the slope coefficients, and for the $\mathrm{AR}(1)$ coefficients.

\subsection{Data Appendix}

Due to problems with the data we needed to impute some of the data values. The three main problems we faced were, top-coding of income, missing values for wages and income, and missing values for hours worked. Here we will briefly outline how we addresses each problem

\subsubsection{Top-Coding of Spouse's Wage, Income from Business and Other Income}

The top-coding of income data in the NLSY varies by year. From 1979 to 1984 all income values above $\$ 75,000$ were truncated to $\$ 75,001$. From 1985 to 1900 all income values greater than $\$ 100,000$ were truncated to $\$ 100,001$. Since this method produced a downward bias in the mean value of income, starting in 1989 all values above the cutoff value were replaced with the average of the true values of income above this level. For our analysis the method used in the later period is acceptable, where as the method used in the earlier period two periods should not result in a bias in our parameter estimates. To adjust the top-coded values in the early years so that they match the values in the latter years we first compute the mean income for the top ten percent of non-top coded values in all years of the data. We then compute the average of the ratio of the top coded values with the mean of the top ten percent of the non-top coded values, across all of the latter years of the data (1989-1994). We multiplied this ratio by the mean of the top ten percent of the non-top coded values in the early years of the data (1979-1984). Finally we replaced the top coded values in the early years with this new value. 


\subsubsection{Imputing Missing Wages and Income}

Once we fixed the top coding problem we then imputed missing wages and income for all individuals in our sample. For individuals who had more than three observations we regressed either log wages or log income on a constant and a time trend and used the results from this regression to impute the missing data. If only one or two values were available, we imputed the missing values with the mean deflated value of the wage or income.

\subsubsection{Imputing Missing Hours Worked}

The NLSY collects information on hours worked each week for every week in the survey. We aggregate these weekly hours worked into hours worked in each year for individuals in our sample. If someone has a missing or invalid value for hours worked in a week we impute the value for that week by taking a weighted mean over all valid values of weekly hours worked in the survey. The weight we use is $0.5 / m$ where $m$ is the difference between the current week and the week of the valid observation. 


\section{References}

Anderson, T.W. and C. Hsiao, "Estimation of Dynamic Models with Error Components." Journal of the American Statistical Association, 76, 598606, 1981.

Angrist, Joshua D. and William N. Evans, "Children and Their Parents' Labor Supply: Evidence from Exogenous Variation is Family Size." The American Economic Review, 80, 450-477, 1998.

Arellano, Manuel and S. Bond, "Some Tests of Specification for Panel Data: Monte Carlo Evidence and an Application to Employment Equations." Review of Economic Studies, 58, 277-297, 1991.

Arellano, Manuel and Olympia. Bover, "Another Look at the Instrumental Variable Estimation of Error-Components Models." Journal of Econometrics 68, 29-51, 1995.

Arellano, Manuel and Raquel Carrasco, "Binary-Choice Panel Data Models with Predetermined Variables," Journal of Econometrics 115, 125-157, 2003.

Arellano, Manuel and Bo Honore, "Panel Data Models: Some Recent Developments," in Heckman, J.J., Leamer, E. (Eds.), Handbook of Econometrics, Vol 5, North-Holland, Amsterdam, 2001.

Balestra, P. and S. Negassi, "A random Coefficient Simultaneous Equation System with an Application to Direct Foreign Investment by French Firms." Empirical Economics, 17, 205-220, 1992.

Blank, Rebecca M., "The Role of Part-Time Work in Women's Labor Market Choices over Time." The American Economic Review, Papers and Proceedings, 79, 295:299, 1989.

Blank, Rebecca M., "Labor Market Dynamics and Part-Time Work," in Solomon Polachek ed., Research in Labor Economics, 17, JAI Press, Greenwich, CT, 1998.

Brooks, Stephen P. and Andrew Gelman, "General Methods for Monitoring Convergence of Iterative Simulations." Journal of Computational and Graphical Statistics, 7, 434-455, 1998.

Browning, Martin, "Children and Household Economic Behavior." Journal of Economic Literature, 30, 1434-1475, 1992.

Buddelmeyer, H. and A. Voicu, "Children and Women's Participation Dynamics: Direct and Indirect Effects." IZA Discussion paper no. 729, 2003. 
Carrasco, Raquel, " Binary Choice with Binary Endogenous Regressors in Panel Data: Estimating the Effect of Fertility on Female Labor Force Participation." Journal of Business and Economic Statistics, 19, 385-394, 2001.

Chamberlain, Gary, "Panel Data," in Griliches, Z, Intriligator, M. (Eds.), Handbook of Econometrics, Vol 2, North-Holland, Amsterdam, 1984.

Chib, Siddhartha, and Greenberg, Edward, "Analysis of Multivariate Probit Models." Biometrika, 85, 347-361, 1998.

Chib, Siddhartha, and Greenberg, Edward, "Hierarchical Analysis of SUR Models with Extensions to Correlated Serial Errors and Time-Varying Parameter Models." Journal of Econometrics, 68, 339-360, 1995.

Chib, Siddhartha, and Ivan Jeliazkov, "Semiparametric Hierarchical Bayes Analysis of Discrete Panel Data with State Dependence and Serial Correlation." Unpublished manuscript, 2003.

Gelman, Andrew and Donald F. Rubin, "Inference form Iterative Simulations Using Multiple Sequences" (with discussion). Statistical Science, 7, 457$511,1992$.

Geweke, John, "Bayesian Inference in Econometric Models Using Monte Carlo Integration." Econometrica, 57,1317-1340,1989.

Geweke, John, "Efficient Simulation from the Multivariate Normal and StudentT Distributions Subject to Linear Constraints," in E. Keramidas and S. Kaufman, Eds., Computing Science and Statistics: Proceedings of the 23rd Symposium on the Interface, 571-578. Fairfax Station, VA: Interface Foundation of North American, 1991.

Geweke, John and Michael P. Keane, "Computationally Intensive Methods for Integrating in Econometrics," in James J. Heckman and Edward Leamer ed., Handbook of Econometrics, Vol. 5, 3463-3568, Elsevier, Amsterdam, 2001.

Geweke, John, Michael P. Keane, and David E. Runkle, "Statistical Inference in the Multinomial Multiperiod Probit Model." Journal of Econometrics, 80, 125-165, 1997.

Giannelli, G. C., "Women's Transitions in the Labor Market: A Competing Risks Analysis on German Panel Data." Journal of Population Economics 9, 287-300, 1996.

Gilks, W. R., C. C. Wang, B Yvonnet and P. Coursaget, "Random-Effects Models for Longitudinal Data Using Gibbs Sampling." Biometrica, 49, 441-453, 1993. 
Hajivassiliou, Vassilis A., "Smooth Simulation Estimation of Panel Data LDV Models" Department of Economics, Yale University, 1990.

Heckman, James J., "Sample Selection Bias as a Specification Error: An Application to Estimation of Female Labor Supply Functions," in James Smith ed., Female Labor Supply, 206-248, Princeton University Press, Princeton, NJ, 1980.

Heckman, James J. and Robert J. Willis, "A Beta-logistic Model for the Analysis of Sequential Labor Force Participation by Married Women." The Journal of Political Economy, 85, 27-58, 1977.

Holz-Eakin, D., Newey, W., and S.H. Rosen, "Estimating Vector Auto-Regressions with Panel Data." Econometrica 56, 1371-1395, 1988.

Honore, B. and E. Kiriazidou, "Panel Data Discrete Choice Models with Lagged Dependent Variables." Econometrica, 68, 839-874, 2000.

Hotz, Joseph, and Robert Miller, "An Empirical Analysis of Life Cycle Fertility and Female Labor Supply." Econometrica, 50, 91-118, 1988

Hyslop, Dean, "State Dependence, Serial Correlation and Heterogeneity in Intertemporal Labor Force Participation of Married Women." Econometrica, 67, 1255-1294, 1999.

Hsiao, Cheng, Trent W. Appelbe, and Christopher R. Dineen, " A General Framework for Panel Data Models with and Application to Canadian Customer-Dialed Long Distance Telephone Service." Journal of Econometrics, 59, 63-86, 1993.

Keane, Michael P., "A Computationally Practical Simulation Estimator for Panel Data." Econometrica, 62, 95-116, 1994.

Kelejian, H. H., "Random Parameters in Simultaneous Equation Framework: Identification and Estimation." Econometrica, 42, 517-527, 1974.

Leibowitz, Arleen, Jacob A. Klerman, and Linda Waite, "Employment of New Mothers and Child Care Choice: Differences by Children's Age." Journal of Human Resources, 27, 112-123, 1992.

McCulloch, Robert and Peter Rossi, "An Exact Analysis of the Multinomial Probit Model." Jornal of Econometrics, 64, 207-240, 1994.

Mincer, Jacob, "Labor Force Participation of Married Women," in H.G. Lewis ed. Aspects of Labor Economics, 63-105, Princeton University Press, Princeton, NJ, 1962.

Mortensen, Dale T., "Job Search and Labor Market Analysis," in: O. Ashenfelter and R. Layard, eds., Handbook of Labor Economics (North-Holland, Amsterdam), 849-919, 1986. 
Nakamura, Alice and Masao Nakamura, "The Econometrics of Female Labor Supply and Children." Econometric Reviews, 11, 1-71, 1992.

Pesaran, Hashem M. and Ron P. Smith, "Estimating Long-Run Relationships from Dynamic Heterogenous Panels." Journal of Econometrics, 68, 79$113,1995$.

Rosenzweig, Mark R. and Kenneth I. Wolpin, "Life-Cycle Labor Supply and Fertility: Causal Inference from Household Models." The Journal of Political Economy, 88, 328-348, 1980.

Shapiro, David, and Frank L. Mott, "Long-Term Employment and Earnings of Women in Relation to Employment Behavior Surrounding First Birth." The Journal of Human Resources, 29, 248-275,1994.

Vella, Francis and Marno Verbeek, "Whose Wages Do Unions Raise? A Dynamic Model of Unionism and Wage Rate Determination for Young Men." Journal of Applied Econometrics, 13, 163-168, 1998.

Vella, Francis and Marno Verbeek, "Two-Step Estimation of Panel Data Models with Censored Endogenous variables and Selection Bias." Journal of Econometrics, 90, 239-263, 1999. 
Table 1: Summary Statistics of Background Variables

\begin{tabular}{|c|c|c|}
\hline & Mean & Standard Deviation \\
\hline Proportion white & 0.69 & 0.46 \\
\hline Proportion black & 0.14 & 0.34 \\
\hline Proportion hispanic & 0.18 & 0.38 \\
\hline Years of schooling of father & 11.63 & 3.82 \\
\hline Years of schooling of mother & 11.28 & 3.14 \\
\hline \multicolumn{3}{|l|}{ Father's labor force status } \\
\hline Full time & 75.91 & \\
\hline Full time part year & 6.02 & \\
\hline Part time & 2.95 & \\
\hline Not Working & 4.66 & \\
\hline \multicolumn{3}{|l|}{ Mother's labor force status } \\
\hline Full time & 29.55 & \\
\hline Full time part year & 9.32 & \\
\hline Part time & 23.07 & \\
\hline Not Working & 34.89 & \\
\hline Mean number of siblings & 3.42 & 2.40 \\
\hline Number of sibling's children & 1.33 & 0.98 \\
\hline Number & 880 & \\
\hline
\end{tabular}


Table 2: Summary Statistics of Time Varying Variables

\begin{tabular}{|c|c|c|c|c|c|c|c|c|c|c|c|}
\hline \multirow[b]{2}{*}{$\begin{array}{l}\text { Year } \\
(1)\end{array}$} & \multirow[b]{2}{*}{$\begin{array}{c}\text { Number at Risk } \\
\text { (2) }\end{array}$} & \multirow[b]{2}{*}{$\begin{array}{l}\text { Age } \\
\text { (3) }\end{array}$} & \multirow[b]{2}{*}{$\begin{array}{c}\text { Education } \\
(4)\end{array}$} & \multirow[b]{2}{*}{$\begin{array}{l}\text { Married } \\
\text { (5) }\end{array}$} & \multirow[b]{2}{*}{$\begin{array}{c}\text { Husband's Income } \\
(6)\end{array}$} & \multirow[b]{2}{*}{$\begin{array}{c}\text { Other Income } \\
(7)\end{array}$} & \multicolumn{5}{|c|}{ Number of Children by Age } \\
\hline & & & & & & & $\begin{array}{c}\text { Children } \\
0 \text { to } 1 \\
(8)\end{array}$ & $\begin{array}{c}\text { Children } \\
2 \text { to } 3 \\
(9)\end{array}$ & $\begin{array}{c}\text { Children } \\
4 \text { to } 5 \\
(10)\end{array}$ & $\begin{array}{c}\text { Children } \\
6 \text { to } 9 \\
(11)\end{array}$ & $\begin{array}{c}\text { Children } \\
10+ \\
(12) \\
\end{array}$ \\
\hline 1979 & 169 & 20.33 & 11.72 & 0.00 & 0.00 & 59.80 & 0.00 & 0.00 & 0.00 & 0.00 & 0.00 \\
\hline 1980 & 275 & 20.74 & 12.01 & 0.21 & 2745.61 & 83.12 & 0.00 & 0.00 & 0.00 & 0.00 & 0.00 \\
\hline 1981 & 387 & 21.33 & 12.23 & 0.28 & 3175.73 & 180.36 & 0.02 & 0.00 & 0.00 & 0.00 & 0.00 \\
\hline 1982 & 500 & 22.03 & 12.52 & 0.36 & 3524.82 & 94.78 & 0.06 & 0.00 & 0.00 & 0.00 & 0.00 \\
\hline 1983 & 600 & 22.76 & 12.78 & 0.44 & 5763.40 & 155.90 & 0.09 & 0.01 & 0.00 & 0.00 & 0.00 \\
\hline 1984 & 681 & 23.57 & 12.96 & 0.51 & 6064.16 & 206.32 & 0.12 & 0.04 & 0.00 & 0.00 & 0.00 \\
\hline 1985 & 758 & 24.42 & 13.22 & 0.58 & 7175.71 & 269.54 & 0.16 & 0.07 & 0.01 & 0.00 & 0.00 \\
\hline 1986 & 817 & 25.32 & 13.39 & 0.64 & 9873.45 & 358.96 & 0.18 & 0.10 & 0.04 & 0.00 & 0.00 \\
\hline 1987 & 859 & 26.22 & 13.54 & 0.71 & 11392.77 & 648.88 & 0.20 & 0.14 & 0.06 & 0.01 & 0.00 \\
\hline 1988 & 880 & 27.19 & 13.64 & 0.77 & 13806.49 & 577.44 & 0.23 & 0.17 & 0.10 & 0.03 & 0.00 \\
\hline 1989 & 880 & 28.19 & 13.67 & 0.83 & 15152.42 & 514.00 & 0.26 & 0.20 & 0.13 & 0.07 & 0.00 \\
\hline 1990 & 880 & 29.19 & 13.70 & 0.89 & 15897.10 & 399.39 & 0.29 & 0.23 & 0.17 & 0.13 & 0.00 \\
\hline 1991 & 880 & 30.19 & 13.73 & 0.94 & 17459.76 & 321.89 & 0.30 & 0.26 & 0.20 & 0.19 & 0.01 \\
\hline 1992 & 880 & 31.19 & 13.79 & 0.97 & 18965.22 & 308.86 & 0.29 & 0.29 & 0.23 & 0.26 & 0.03 \\
\hline 1993 & 880 & 32.19 & 13.81 & 1.00 & 19171.69 & 586.76 & 0.29 & 0.30 & 0.26 & 0.33 & 0.07 \\
\hline
\end{tabular}


Table 3. Estimation results. Posterior means and standard deviations for the coefficients.

\begin{tabular}{lcccccccc}
\hline \hline & \multicolumn{2}{c}{ FT-NW } & \multicolumn{2}{c}{ FP-NW } & \multicolumn{2}{c}{ PT-NW } & \multicolumn{2}{c}{ Fertility } \\
\cline { 2 - 8 } & Mean & PSTD & Mean & PSTD & Mean & PSTD & Mean & PSTD \\
\hline Variable & $(1)$ & $(2)$ & $(3)$ & $(4)$ & $(5)$ & $(6)$ & $(7)$ & $(8)$ \\
\hline Constant & -0.325 & 0.176 & -0.988 & 0.131 & -1.129 & 0.151 & -1.330 & 0.063 \\
Children age 0-1 & -1.032 & 0.127 & -0.829 & 0.117 & -0.124 & 0.092 & 0.292 & 0.055 \\
Children age 2-4 & -0.769 & 0.153 & -0.606 & 0.119 & -0.130 & 0.090 & 0.045 & 0.053 \\
Children age 5+ & -0.614 & 0.135 & -0.547 & 0.096 & -0.107 & 0.089 & -0.372 & 0.068 \\
Married & -0.984 & 0.112 & -0.474 & 0.102 & -0.684 & 0.121 & & \\
Spouse's wage & 0.013 & 0.011 & -0.003 & 0.010 & 0.016 & 0.011 & & \\
Other income & -0.021 & 0.013 & -0.044 & 0.012 & -0.027 & 0.013 & 0.031 & 0.006 \\
Region & & & & & & & & \\
$\quad$ North East & -0.114 & 0.152 & -0.296 & 0.103 & -0.297 & 0.128 & -0.067 & 0.052 \\
\multicolumn{1}{c}{ North Central } & 0.397 & 0.151 & 0.085 & 0.104 & 0.095 & 0.121 & 0.008 & 0.051 \\
Urban & 0.325 & 0.143 & 0.008 & 0.098 & -0.196 & 0.118 & -0.030 & 0.049 \\
Wage & 0.150 & 0.113 & -0.121 & 0.083 & -0.108 & 0.096 & -0.013 & 0.045 \\
Sibling with kids & 0.511 & 0.012 & 0.511 & 0.012 & 0.511 & 0.012 & & \\
$\rho$ & & & & & & & 0.023 & 0.009 \\
\hline \hline
\end{tabular}

Note: FT=Full time; FP=Full time part year; $\mathrm{PT}=$ Part time; NW=Non work 
Table 4. Posterior means of random coefficients. Observed heterogeneity.

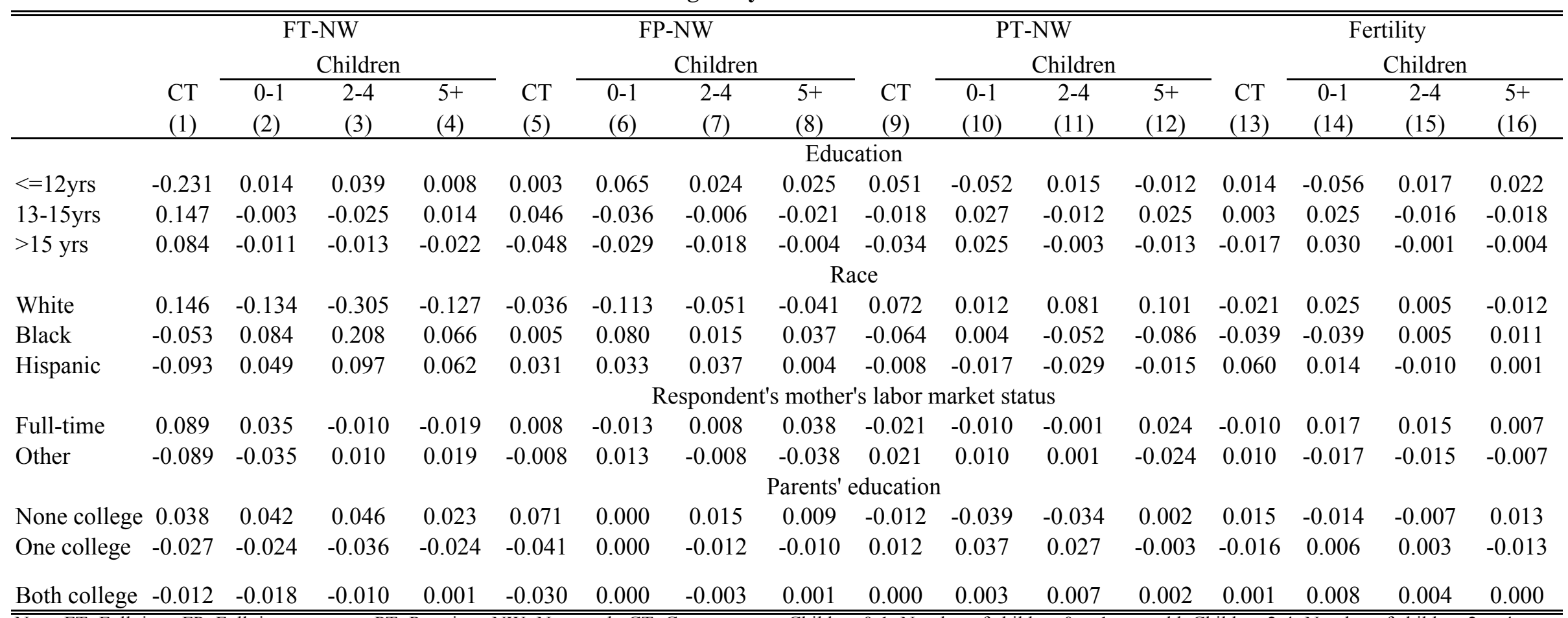

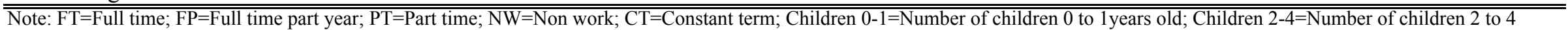
years old; Children $5+=$ Number of children five years old and older. Age is age at last birthday. 
Table 5. Posterior correlation matrix for the effects of unobserved individual heterogeneity

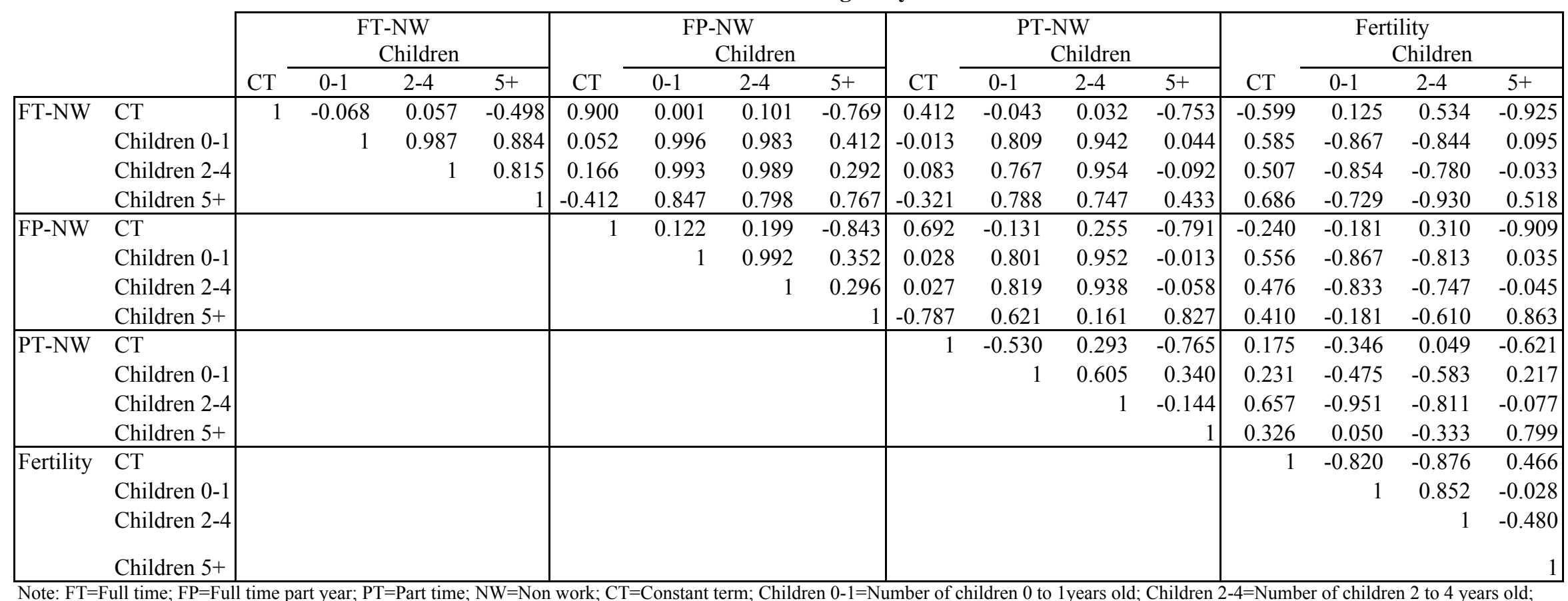

Children $5+=$ Number of children five years old and older. Age is age at last birthday. 
Table 6: Post-Birth Simulation scenarios

\begin{tabular}{|c|c|c|c|c|c|c|c|c|c|}
\hline & & year 1 & year 2 & year 3 & year 4 & year 5 & year 6 & year 7 & year 8 \\
\hline Marital Status & & 0 & 1 & 1 & 1 & 1 & 1 & 1 & 1 \\
\hline & & \multicolumn{8}{|c|}{ Fertility histories } \\
\hline Fertility & 0 & 0 & 0 & 0 & 0 & 0 & 0 & 0 & 0 \\
\hline Children 0-1 & 0 & 0 & 0 & 0 & 0 & 0 & 0 & 0 & 0 \\
\hline Children 2-4 & 0 & 0 & 0 & 0 & 0 & 0 & 0 & 0 & 0 \\
\hline Children 5+ & 0 & 0 & 0 & 0 & 0 & 0 & 0 & 0 & 0 \\
\hline Fertility & 1 & 0 & 1 & 0 & 0 & 0 & 0 & 0 & 0 \\
\hline Children 0-1 & 1 & 0 & 0 & 1 & 1 & 0 & 0 & 0 & 0 \\
\hline Children 2-4 & 1 & 0 & 0 & 0 & 0 & 1 & 1 & 1 & 0 \\
\hline Children 5+ & 1 & 0 & 0 & 0 & 0 & 0 & 0 & 0 & 1 \\
\hline Fertility & 2 & 0 & 1 & 0 & 1 & 0 & 0 & 0 & 0 \\
\hline Children 0-1 & 2 & 0 & 0 & 1 & 1 & 1 & 1 & 0 & 0 \\
\hline Children 2-4 & 2 & 0 & 0 & 0 & 0 & 1 & 1 & 2 & 1 \\
\hline Children 5+ & 2 & 0 & 0 & 0 & 0 & 0 & 0 & 0 & 1 \\
\hline
\end{tabular}

Note: Children 0-1=Number of children 0 to 1years old; Children 2-4=Number of children 2 to 4 years old; Children $5+=$ Number of children five years old and older. Age is age at last birthday. 
Table 7: Probabilities of returning to full-time work following birth and spells in alternative labor martket states conditional on working full time in the two years prior to the birth. By education

\begin{tabular}{|c|c|c|c|c|c|c|c|c|c|c|c|c|c|c|c|c|}
\hline & \multicolumn{4}{|c|}{ Full-time } & \multicolumn{4}{|c|}{ Full-time part-year } & \multicolumn{4}{|c|}{ Part-time } & \multicolumn{4}{|c|}{ Non work } \\
\hline \multirow{3}{*}{ Year } & $\begin{array}{l}\text { One } \\
\text { interr }\end{array}$ & $\begin{array}{l}\text {-year } \\
\text { uption }\end{array}$ & $\begin{array}{r}\text { Two } \\
\text { interr } \\
\end{array}$ & ion & $\begin{array}{l}\text { One- } \\
\text { interr }\end{array}$ & $\begin{array}{l}\text { year } \\
\text { ption }\end{array}$ & $\begin{array}{l}\text { Two } \\
\text { interr }\end{array}$ & $\begin{array}{l}\text {-year } \\
\text { uption }\end{array}$ & $\begin{array}{r}\text { On } \\
\text { inter }\end{array}$ & $\begin{array}{l}\text { year } \\
\text { iption }\end{array}$ & $\begin{array}{r}\mathrm{Tw} \\
\text { inter }\end{array}$ & ion & $\begin{array}{l}\text { One } \\
\text { interr }\end{array}$ & $\begin{array}{l}\text { year } \\
\text { uption }\end{array}$ & $\begin{array}{l}\text { Two } \\
\text { inter }\end{array}$ & $\begin{array}{l}\text { ear } \\
\text { tion }\end{array}$ \\
\hline & $\begin{array}{c}\text { No } \\
\text { child } \\
\text { (1) }\end{array}$ & $\begin{array}{c}\text { Child } \\
\text { (2) }\end{array}$ & $\begin{array}{l}\text { No } \\
\text { child } \\
(3)\end{array}$ & $\begin{array}{c}\text { Child } \\
(4)\end{array}$ & $\begin{array}{l}\text { No } \\
\text { child } \\
(5)\end{array}$ & $\begin{array}{c}\text { Child } \\
\text { (6) }\end{array}$ & $\begin{array}{l}\text { No } \\
\text { child } \\
(7)\end{array}$ & $\begin{array}{c}\text { Child } \\
(8)\end{array}$ & $\begin{array}{c}\text { No } \\
\text { child } \\
(9)\end{array}$ & $\begin{array}{c}\text { Child } \\
(10)\end{array}$ & $\begin{array}{l}\text { No } \\
\text { child } \\
(11)\end{array}$ & $\begin{array}{c}\text { Child } \\
(12)\end{array}$ & $\begin{array}{l}\text { No } \\
\text { child } \\
\text { (13) }\end{array}$ & $\begin{array}{c}\text { Child } \\
(14)\end{array}$ & $\begin{array}{l}\text { No } \\
\text { child } \\
(15)\end{array}$ & $\begin{array}{c}\text { Child } \\
\text { (16) }\end{array}$ \\
\hline & \multicolumn{16}{|c|}{ Education $<=12$ years } \\
\hline 4 & 0.664 & 0.486 & - & - & 0.404 & 0.227 & - & - & 0.338 & 0.189 & - & - & 0.329 & 0.187 & - & - \\
\hline 5 & 0.568 & 0.394 & 0.671 & 0.529 & 0.437 & 0.269 & 0.346 & 0.222 & 0.401 & 0.245 & 0.294 & 0.180 & 0.385 & 0.247 & 0.278 & 0.193 \\
\hline 6 & 0.520 & 0.342 & 0.571 & 0.411 & 0.445 & 0.273 & 0.403 & 0.248 & 0.428 & 0.259 & 0.376 & 0.228 & 0.417 & 0.257 & 0.357 & 0.229 \\
\hline 7 & 0.495 & 0.311 & 0.522 & 0.348 & 0.450 & 0.273 & 0.427 & 0.259 & 0.441 & 0.267 & 0.415 & 0.250 & 0.433 & 0.263 & 0.398 & 0.246 \\
\hline 8 & 0.481 & 0.357 & 0.497 & 0.387 & 0.455 & 0.322 & 0.439 & 0.319 & 0.449 & 0.324 & 0.435 & 0.315 & 0.444 & 0.320 & 0.423 & 0.309 \\
\hline \multicolumn{17}{|c|}{ Education $13-15$ years } \\
\hline 4 & 0.750 & 0.574 & - & - & 0.496 & 0.313 & - & - & 0.415 & 0.259 & - & - & 0.406 & 0.260 & - & - \\
\hline 5 & 0.680 & 0.480 & 0.758 & 0.595 & 0.551 & 0.358 & 0.448 & 0.290 & 0.506 & 0.333 & 0.382 & 0.249 & 0.489 & 0.328 & 0.365 & 0.250 \\
\hline 6 & 0.641 & 0.434 & 0.682 & 0.490 & 0.571 & 0.368 & 0.522 & 0.333 & 0.545 & 0.357 & 0.485 & 0.315 & 0.534 & 0.348 & 0.464 & 0.307 \\
\hline 7 & 620 & 0.409 & 0.642 & 439 & 580 & 0.371 & 555 & & 0.567 & 0.370 & 0.542 & 0.348 & 0.559 & 0.360 & 0.523 & 0.334 \\
\hline 8 & 0.611 & 0.491 & 0.623 & 0.514 & 0.587 & 0.462 & 0.574 & 0.450 & 0.579 & 0.461 & 0.568 & 0.445 & 0.573 & 0.458 & 0.551 & 0.442 \\
\hline \multicolumn{17}{|c|}{ Education $>=16$ years } \\
\hline 4 & 0.791 & 0.637 & - & - & 0.552 & 0.364 & - & - & 0.482 & 0.298 & - & - & 0.446 & 0.301 & - & - \\
\hline 5 & 0.732 & 0.552 & 0.795 & 0.659 & 0.613 & 0.421 & 0.501 & & 0.576 & 0.388 & 0.425 & 0.292 & 0.540 & 0.383 & 0.406 & 0.300 \\
\hline 6 & 0.706 & 0.507 & 0.740 & 0.560 & 0.635 & 0.434 & 0.582 & 0.399 & 0.619 & 0.420 & 0.542 & 0.375 & 0.592 & 0.412 & 0.524 & 0.367 \\
\hline 7 & 0.687 & 0.487 & 0.705 & 516 & 0.649 & 0.441 & 0.619 & 0.422 & 0.639 & 0.433 & 0.597 & 0.410 & 0.621 & 0.429 & 0.584 & 0.405 \\
\hline 8 & 0.678 & 0.568 & 0.687 & 0.585 & 0.658 & 0.535 & 0.635 & 0.527 & 0.649 & 0.531 & 0.625 & 0.521 & 0.641 & 0.527 & 0.618 & 0.514 \\
\hline
\end{tabular}

Note: Estimates are for white women whose mother did not work full time and with one parent with a college education. 
Table 8: Probabilities of returning to full-time work following birth and spells in alternative labor martket states conditional on working full time in the two years prior to the birth. By Race

\begin{tabular}{|c|c|c|c|c|c|c|c|c|c|c|c|c|c|c|c|c|}
\hline & \multicolumn{4}{|c|}{ Full-time } & \multicolumn{4}{|c|}{ Full-time part-year } & \multicolumn{4}{|c|}{ Part-time } & \multicolumn{4}{|c|}{ Non work } \\
\hline & $\begin{array}{l}\text { One- } \\
\text { interru }\end{array}$ & $\begin{array}{l}\text { year } \\
\text { ption }\end{array}$ & $\begin{array}{l}\text { Two } \\
\text { interr }\end{array}$ & $\begin{array}{l}\text {-year } \\
\text { aption }\end{array}$ & $\begin{array}{l}\text { One- } \\
\text { interr }\end{array}$ & $\begin{array}{l}\text { year } \\
\text { ption }\end{array}$ & $\begin{array}{r}\text { Two } \\
\text { interr }\end{array}$ & $\begin{array}{l}\text {-year } \\
\text { aption }\end{array}$ & $\begin{array}{l}\text { One- } \\
\text { interr }\end{array}$ & $\begin{array}{l}\text { year } \\
\text { iption }\end{array}$ & $\begin{array}{l}\text { Two } \\
\text { interr }\end{array}$ & tion & $\begin{array}{l}\text { One- } \\
\text { interr }\end{array}$ & $\begin{array}{l}\text { year } \\
\text { ption }\end{array}$ & $\begin{array}{l}\text { Two } \\
\text { interr }\end{array}$ & ear \\
\hline \multirow[t]{2}{*}{ Year } & $\begin{array}{c}\text { No } \\
\text { child } \\
(1)\end{array}$ & $\begin{array}{c}\text { Child } \\
\text { (2) }\end{array}$ & $\begin{array}{c}\text { No } \\
\text { child } \\
(3)\end{array}$ & $\begin{array}{c}\text { Child } \\
\text { (4) }\end{array}$ & $\begin{array}{l}\text { No } \\
\text { child } \\
(5)\end{array}$ & $\begin{array}{c}\text { Child } \\
\text { (6) }\end{array}$ & $\begin{array}{l}\text { No } \\
\text { child } \\
(7)\end{array}$ & $\begin{array}{c}\text { Child } \\
\text { (8) }\end{array}$ & $\begin{array}{c}\text { No } \\
\text { child } \\
(9)\end{array}$ & $\begin{array}{c}\text { Child } \\
(10)\end{array}$ & $\begin{array}{l}\text { No } \\
\text { child } \\
(11)\end{array}$ & $\begin{array}{c}\text { Child } \\
\text { (12) }\end{array}$ & $\begin{array}{l}\text { No } \\
\text { child } \\
(13)\end{array}$ & $\begin{array}{c}\text { Child } \\
(14)\end{array}$ & $\begin{array}{l}\text { No } \\
\text { child } \\
(15)\end{array}$ & $\begin{array}{c}\text { Child } \\
\text { (16) }\end{array}$ \\
\hline & \multicolumn{16}{|c|}{ White } \\
\hline 4 & 0.664 & 0.486 & - & - & 0.404 & 0.227 & - & - & 0.338 & 0.189 & - & - & 0.329 & 0.187 & - & - \\
\hline 5 & 0.568 & 0.394 & 0.671 & 0.529 & 0.437 & 0.269 & 0.346 & 0.222 & 0.401 & 0.245 & 0.294 & 0.180 & 0.385 & 0.247 & 0.278 & 0.193 \\
\hline 6 & 0.520 & 0.342 & 0.571 & 0.411 & 0.445 & 0.273 & 0.403 & 0.248 & 0.428 & 0.259 & 0.376 & 0.228 & 0.417 & 0.257 & 0.357 & 0.229 \\
\hline 7 & 0.495 & 0.311 & 0.522 & 0.348 & 0.450 & 0.273 & 0.427 & 0.259 & 0.441 & 0.267 & 0.415 & 0.250 & 0.433 & 0.263 & 0.398 & 0.246 \\
\hline \multirow[t]{2}{*}{8} & 0.481 & 0.357 & 0.497 & 0.387 & 0.455 & 0.322 & 0.439 & 0.319 & 0.449 & 0.324 & 0.435 & 0.315 & 0.444 & 0.320 & 0.423 & 0.309 \\
\hline & \multicolumn{16}{|c|}{ Black } \\
\hline 4 & 0.637 & 0.486 & - & - & 0.374 & 0.232 & - & - & 0.317 & 0.195 & - & - & 0.302 & 0.186 & - & - \\
\hline 5 & 0.535 & 0.481 & 0.644 & 0.624 & 0.405 & 0.352 & 0.321 & 0.306 & 0.371 & 0.326 & 0.270 & 0.258 & 0.352 & 0.323 & 0.255 & 0.267 \\
\hline 6 & 0.484 & 0.419 & 0.539 & 0.488 & 0.411 & 0.350 & 0.372 & 0.329 & 0.394 & 0.339 & 0.343 & 0.304 & 0.380 & 0.333 & 0.325 & 0.300 \\
\hline 7 & 0.458 & 0.386 & 0.489 & 0.421 & 0.415 & 0.349 & 0.394 & 0.336 & 0.406 & 0.343 & 0.378 & 0.324 & 0.397 & 0.339 & 0.363 & 0.319 \\
\hline 8 & 0.440 & 0.363 & 0.456 & 0.382 & 0.415 & 0.344 & 0.405 & 0.329 & 0.411 & 0.339 & 0.395 & 0.327 & 0.405 & 0.335 & 0.385 & 0.323 \\
\hline \multicolumn{17}{|c|}{ Hispanic } \\
\hline 4 & 0.625 & 0.478 & - & - & 0.367 & 0.221 & - & - & 0.310 & 0.185 & - & - & 0.292 & 0.181 & - & - \\
\hline 5 & 0.521 & 0.444 & 0.629 & 0.586 & 0.394 & 0.315 & 0.312 & 0.270 & 0.361 & 0.290 & 0.259 & 0.224 & 0.341 & 0.289 & 0.248 & 0.235 \\
\hline 6 & 0.469 & 0.383 & 0.524 & 0.451 & 0.401 & 0.312 & 0.358 & 0.292 & 0.384 & 0.298 & 0.333 & 0.265 & 0.367 & 0.297 & 0.316 & 0.266 \\
\hline 7 & 0.440 & 0.352 & 0.468 & 0.390 & 0.402 & 0.311 & 0.381 & 0.299 & 0.397 & 0.302 & 0.369 & 0.285 & 0.380 & 0.301 & 0.350 & 0.285 \\
\hline 8 & 0.425 & 0.356 & 0.440 & 0.382 & 0.404 & 0.325 & 0.387 & 0.320 & 0.400 & 0.321 & 0.384 & 0.312 & 0.391 & 0.320 & 0.370 & 0.306 \\
\hline
\end{tabular}

Note: Estimates are for white women whose mother did not work full time and with one parent with a college education. 
Table 9: Direct and Indirect effects of children. By Education and Race Controling for Individual Heterogeneity

\begin{tabular}{|c|c|c|c|c|c|c|}
\hline \multirow[b]{3}{*}{ Year } & \multicolumn{4}{|c|}{ First birth } & \multicolumn{2}{|c|}{ Second birth } \\
\hline & \multicolumn{2}{|c|}{ One-year interruption } & \multicolumn{2}{|c|}{ Two-year interruption } & \multicolumn{2}{|c|}{ One-year interruption } \\
\hline & $\begin{array}{c}\text { Indirect } \\
(1)\end{array}$ & $\begin{array}{l}\text { Direct } \\
(2)\end{array}$ & $\begin{array}{c}\text { Indirect } \\
\text { (3) }\end{array}$ & $\begin{array}{c}\text { Direct } \\
(4) \\
\end{array}$ & $\begin{array}{c}\text { Indirect } \\
(6)\end{array}$ & $\begin{array}{c}\text { Direct } \\
(7)\end{array}$ \\
\hline \multicolumn{7}{|c|}{ White, education $<=12$ years } \\
\hline 4 & 0.100 & 0.148 & - & - & - & - \\
\hline 5 & 0.054 & 0.149 & 0.105 & 0.098 & - & - \\
\hline 6 & 0.030 & 0.164 & 0.058 & 0.136 & 0.048 & 0.092 \\
\hline 7 & 0.018 & 0.173 & 0.034 & 0.157 & 0.025 & 0.085 \\
\hline 8 & 0.011 & 0.123 & 0.021 & 0.114 & 0.016 & 0.135 \\
\hline \multicolumn{7}{|c|}{ White, Education $13-15$ years } \\
\hline 4 & 0.097 & 0.155 & - & - & - & - \\
\hline 5 & 0.053 & 0.178 & 0.107 & 0.124 & - & - \\
\hline 6 & 0.030 & 0.192 & 0.060 & 0.162 & 0.060 & 0.119 \\
\hline 7 & 0.017 & 0.201 & 0.034 & 0.184 & 0.032 & 0.123 \\
\hline 8 & 0.011 & 0.118 & 0.021 & 0.108 & 0.019 & 0.187 \\
\hline \multicolumn{7}{|c|}{ White, Education $>=16$ years } \\
\hline 4 & 0.085 & 0.152 & - & - & - & - \\
\hline 5 & 0.046 & 0.172 & 0.099 & 0.119 & - & - \\
\hline 6 & 0.027 & 0.191 & 0.056 & 0.162 & 0.072 & 0.129 \\
\hline 7 & 0.016 & 0.198 & 0.032 & 0.181 & 0.041 & 0.137 \\
\hline 8 & 0.009 & 0.112 & 0.019 & 0.102 & 0.023 & 0.201 \\
\hline \multicolumn{7}{|c|}{ Black, education $<=12$ years } \\
\hline 4 & 0.081 & 0.124 & - & - & - & - \\
\hline 5 & 0.044 & 0.042 & 0.087 & -0.001 & - & - \\
\hline 6 & 0.025 & 0.055 & 0.049 & 0.031 & 0.051 & 0.093 \\
\hline 7 & 0.015 & 0.063 & 0.029 & 0.049 & 0.027 & 0.031 \\
\hline 8 & 0.008 & 0.075 & 0.017 & 0.066 & 0.016 & 0.047 \\
\hline \multicolumn{7}{|c|}{ Hispanic education $<=12$ years } \\
\hline 4 & 0.082 & 0.122 & - & - & - & - \\
\hline 5 & 0.044 & 0.064 & 0.086 & 0.022 & - & - \\
\hline 6 & 0.025 & 0.077 & 0.049 & 0.053 & 0.047 & 0.090 \\
\hline 7 & 0.014 & 0.084 & 0.028 & 0.070 & 0.026 & 0.043 \\
\hline 8 & 0.008 & 0.070 & 0.017 & 0.062 & 0.016 & 0.070 \\
\hline
\end{tabular}


Table 10: Pre-Birth Simulation scenarios

\begin{tabular}{|c|c|c|c|c|c|c|c|c|c|}
\hline & & year 1 & year 2 & year 3 & year 4 & year 5 & year 6 & year 7 & year 8 \\
\hline \multicolumn{2}{|l|}{ Marital Status } & 0 & 0 & 1 & 1 & 1 & 1 & 1 & 1 \\
\hline & & \multicolumn{8}{|c|}{ Fertility histories } \\
\hline Fertility & 0 & 0 & 0 & 0 & 0 & 0 & 0 & 0 & 0 \\
\hline Children 0-1 & 0 & 0 & 0 & 0 & 0 & 0 & 0 & 0 & 0 \\
\hline Children 2-4 & 0 & 0 & 0 & 0 & 0 & 0 & 0 & 0 & 0 \\
\hline Children 5+ & 0 & 0 & 0 & 0 & 0 & 0 & 0 & 0 & 0 \\
\hline Fertility & 1 & 0 & 0 & 0 & 1 & 0 & 0 & 0 & 0 \\
\hline Children 0-1 & 1 & 0 & 0 & 0 & 0 & 1 & 1 & 0 & 0 \\
\hline Children 2-4 & 1 & 0 & 0 & 0 & 0 & 0 & 0 & 1 & 1 \\
\hline Children 5+ & 1 & 0 & 0 & 0 & 0 & 0 & 0 & 0 & 0 \\
\hline Fertility & 2 & 0 & 0 & 0 & 1 & 0 & 1 & 0 & 0 \\
\hline Children 0-1 & 2 & 0 & 0 & 0 & 0 & 1 & 1 & 1 & 1 \\
\hline Children 2-4 & 2 & 0 & 0 & 0 & 0 & 0 & 0 & 1 & 1 \\
\hline Children 5+ & 2 & 0 & 0 & 0 & 0 & 0 & 0 & 0 & 0 \\
\hline
\end{tabular}

Note: Children 0-1=Number of children 0 to 1years old; Children 2-4=Number of children 2 to 4 years old; Children $5+=$ Number of children five years old and older. Age is age at last birthday. 
Appendix Table 1: Direct and Indirect effects of children. By Education and Race Not Controling for Individual Heterogeneity

\begin{tabular}{|c|c|c|c|c|c|c|}
\hline \multirow[b]{3}{*}{ Year } & \multicolumn{4}{|c|}{ First birth } & \multirow{2}{*}{\multicolumn{2}{|c|}{$\begin{array}{c}\text { Second birth } \\
\text { One-year interruption }\end{array}$}} \\
\hline & \multicolumn{2}{|c|}{ One-year interruption } & \multicolumn{2}{|c|}{ Two-year interruption } & & \\
\hline & $\begin{array}{c}\text { Indirect } \\
(1)\end{array}$ & $\begin{array}{l}\text { Direct } \\
(2) \\
\end{array}$ & $\begin{array}{c}\text { Indirect } \\
\text { (3) }\end{array}$ & $\begin{array}{c}\text { Direct } \\
(4)\end{array}$ & $\begin{array}{c}\text { Indirect } \\
(6)\end{array}$ & $\begin{array}{l}\text { Direct } \\
(7) \\
\end{array}$ \\
\hline \multicolumn{7}{|c|}{ White, education $<=12$ years } \\
\hline 4 & 0.153 & 0.139 & --- & --- & --- & --- \\
\hline 5 & 0.115 & 0.133 & 0.185 & 0.063 & --- & --- \\
\hline 6 & 0.099 & 0.147 & 0.156 & 0.091 & 0.086 & 0.099 \\
\hline 7 & 0.078 & 0.145 & 0.120 & 0.103 & 0.051 & 0.133 \\
\hline 8 & 0.069 & 0.138 & 0.108 & 0.100 & 0.035 & 0.137 \\
\hline \multicolumn{7}{|c|}{ White, Education $13-15$ years } \\
\hline 4 & 0.113 & 0.108 & --- & --- & --- & --- \\
\hline 5 & 0.080 & 0.123 & 0.131 & 0.071 & --- & --- \\
\hline 6 & 0.064 & 0.150 & 0.101 & 0.113 & 0.112 & 0.111 \\
\hline 7 & 0.049 & 0.128 & 0.078 & 0.099 & 0.081 & 0.140 \\
\hline 8 & 0.037 & 0.084 & 0.059 & 0.061 & 0.061 & 0.147 \\
\hline \multicolumn{7}{|c|}{ White, Education $>=16$ years } \\
\hline 4 & 0.064 & 0.061 & --- & --- & --- & --- \\
\hline 5 & 0.047 & 0.081 & 0.076 & 0.052 & --- & --- \\
\hline 6 & 0.032 & 0.086 & 0.052 & 0.066 & 0.146 & 0.098 \\
\hline 7 & 0.024 & 0.092 & 0.038 & 0.078 & 0.112 & 0.138 \\
\hline 8 & 0.018 & 0.030 & 0.028 & 0.020 & 0.086 & 0.165 \\
\hline \multicolumn{7}{|c|}{ Black, education $<=12$ years } \\
\hline 4 & 0.083 & 0.103 & --- & --- & --- & --- \\
\hline 5 & 0.057 & -0.024 & 0.107 & -0.074 & --- & --- \\
\hline 6 & 0.044 & -0.013 & 0.080 & -0.050 & 0.036 & 0.037 \\
\hline 7 & 0.039 & 0.005 & 0.069 & -0.025 & 0.028 & -0.060 \\
\hline 8 & 0.027 & 0.045 & 0.048 & 0.024 & 0.022 & -0.039 \\
\hline \multicolumn{7}{|c|}{ Hispanic education $<=12$ years } \\
\hline 4 & 0.077 & 0.069 & --- & --- & --- & --- \\
\hline 5 & 0.055 & 0.012 & 0.088 & -0.021 & --- & --- \\
\hline 6 & 0.039 & 0.003 & 0.064 & -0.022 & 0.024 & 0.042 \\
\hline 7 & 0.029 & 0.001 & 0.047 & -0.017 & 0.018 & -0.019 \\
\hline 8 & 0.020 & 0.049 & 0.033 & 0.036 & 0.018 & -0.057 \\
\hline
\end{tabular}


Appendix Table 2. Convergence Study. Scale reduction factors

\begin{tabular}{lcccc}
\hline \hline Variable & FT-NW & FP-NW & PT-NW & Fertility \\
\hline Constant & 1.0145 & 1.0205 & 1.0212 & 1.0014 \\
Kid age 0-1 & 1.1040 & 1.0646 & 1.1898 & 1.0161 \\
Kid age 2-4 & 1.1093 & 1.0428 & 1.0204 & 1.0060 \\
Kid age 5+ & 1.0660 & 1.1032 & 1.0611 & 1.0854 \\
Married & 1.0011 & 1.0048 & 1.0015 & \\
Spouse's wage & 1.0057 & 1.0056 & 1.0003 & \\
Other income & 1.0016 & 1.0010 & 1.0006 & 1.0081 \\
Region & & & & \\
$\quad$ North East & 1.0024 & 1.0019 & 1.0095 & 1.0009 \\
\multicolumn{1}{c}{ North Central } & 1.0065 & 1.0145 & 1.0132 & 1.0063 \\
$\quad$ South & 1.0019 & 1.0039 & 1.0114 & 1.0072 \\
Urban & 1.0146 & 1.0163 & 1.0208 & 1.0011 \\
Wage & 1.0441 & 1.0441 & 1.0441 & \\
Sibling with kids & & & & 1.0008 \\
$\rho$ & 1.0122 & 1.0050 & 1.0090 & 1.0047 \\
\hline \hline
\end{tabular}

Note: $\mathrm{FT}=$ Full time; $\mathrm{FP}=$ Full time part year; $\mathrm{PT}=$ Part time; $\mathrm{NW}=$ Non work 
Figure 1-Labor Force Participation Rates for At Risk Women

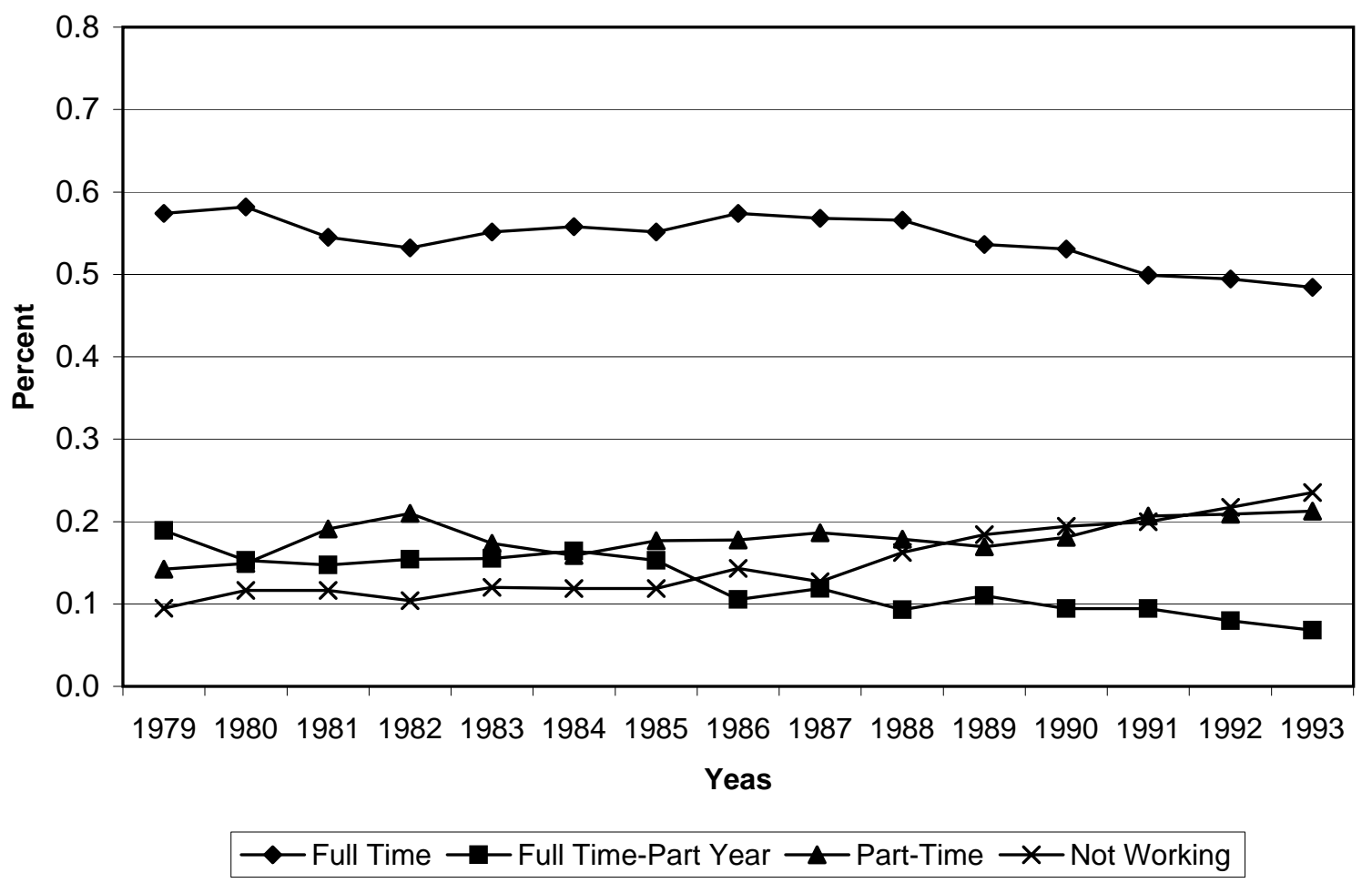


Figure 2: Birth Rate for At Risk Women

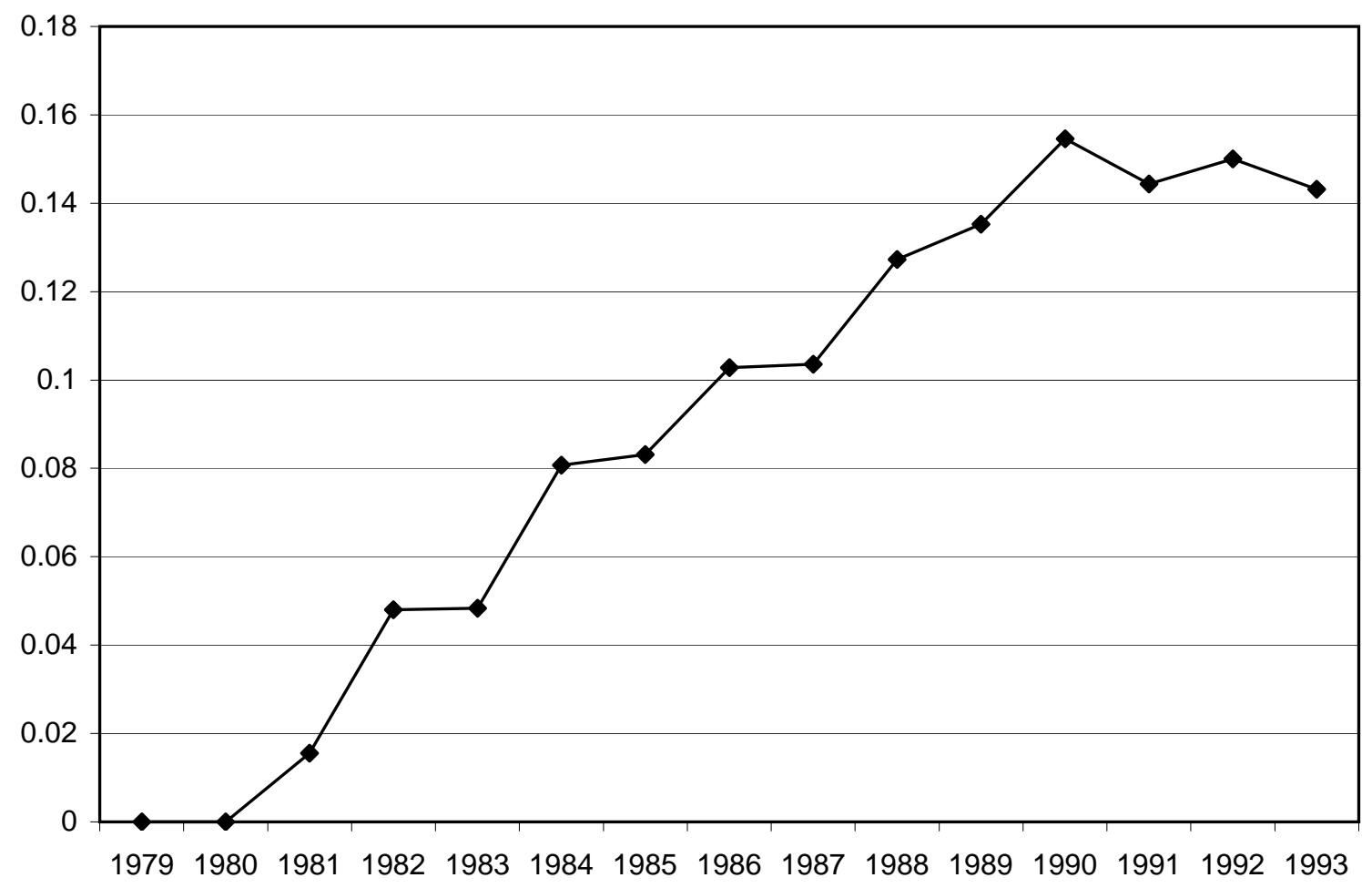


Figure 3-Labor Force Participation Rates for Women with 1 Child by 1993

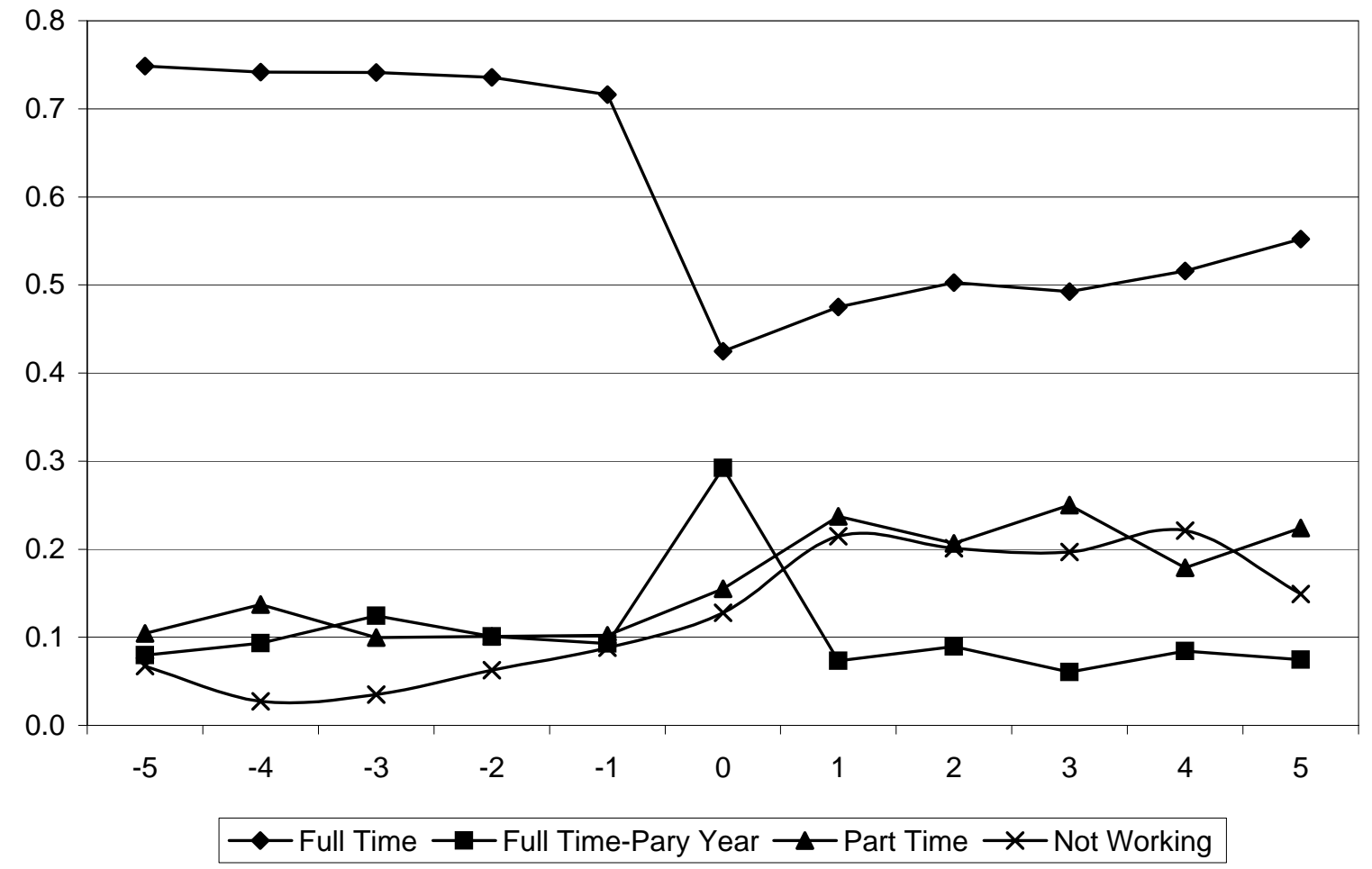


Figure 4-Labor Force Participation Rates for Women with 2 Children by 1993

First Birth

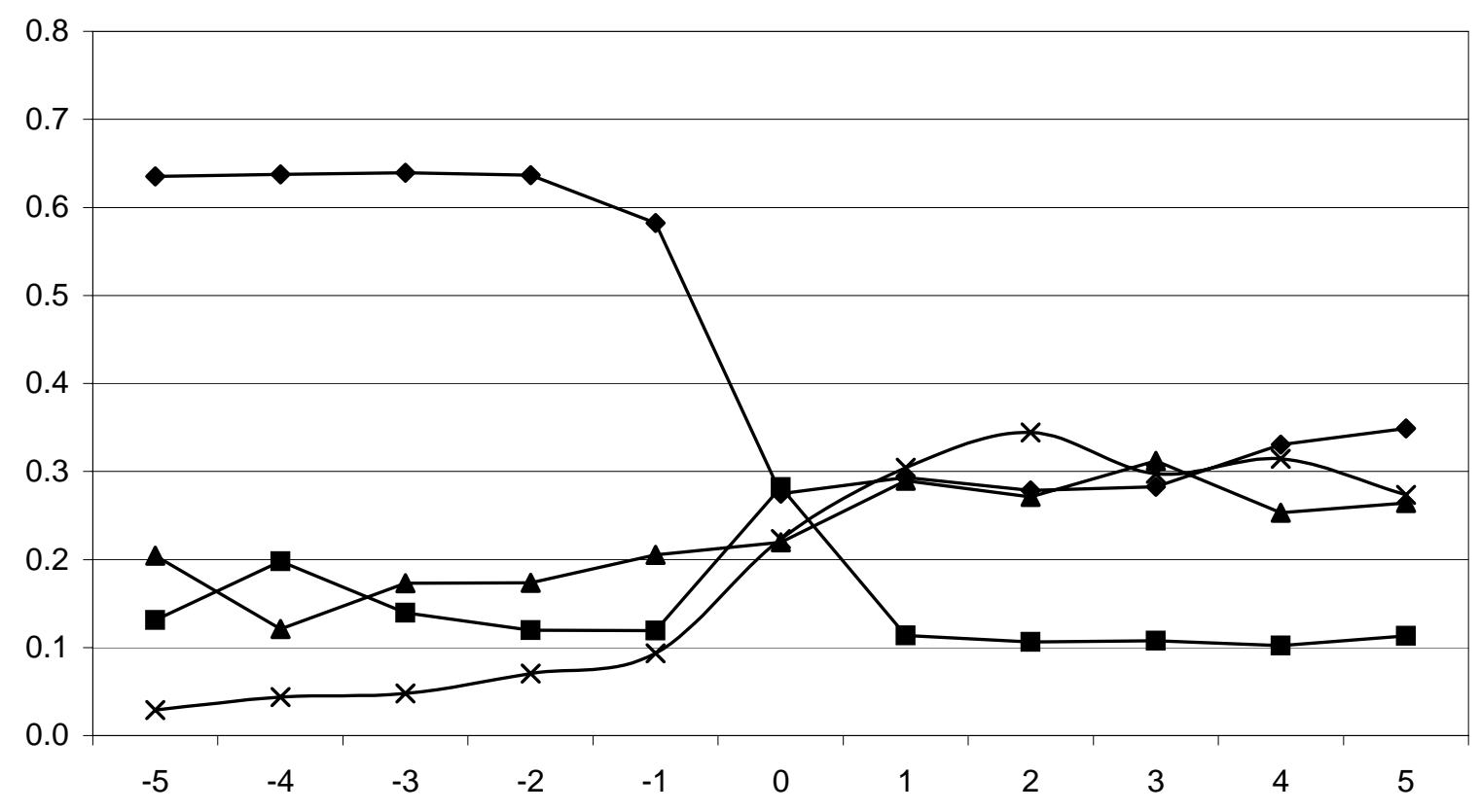

Second Birth

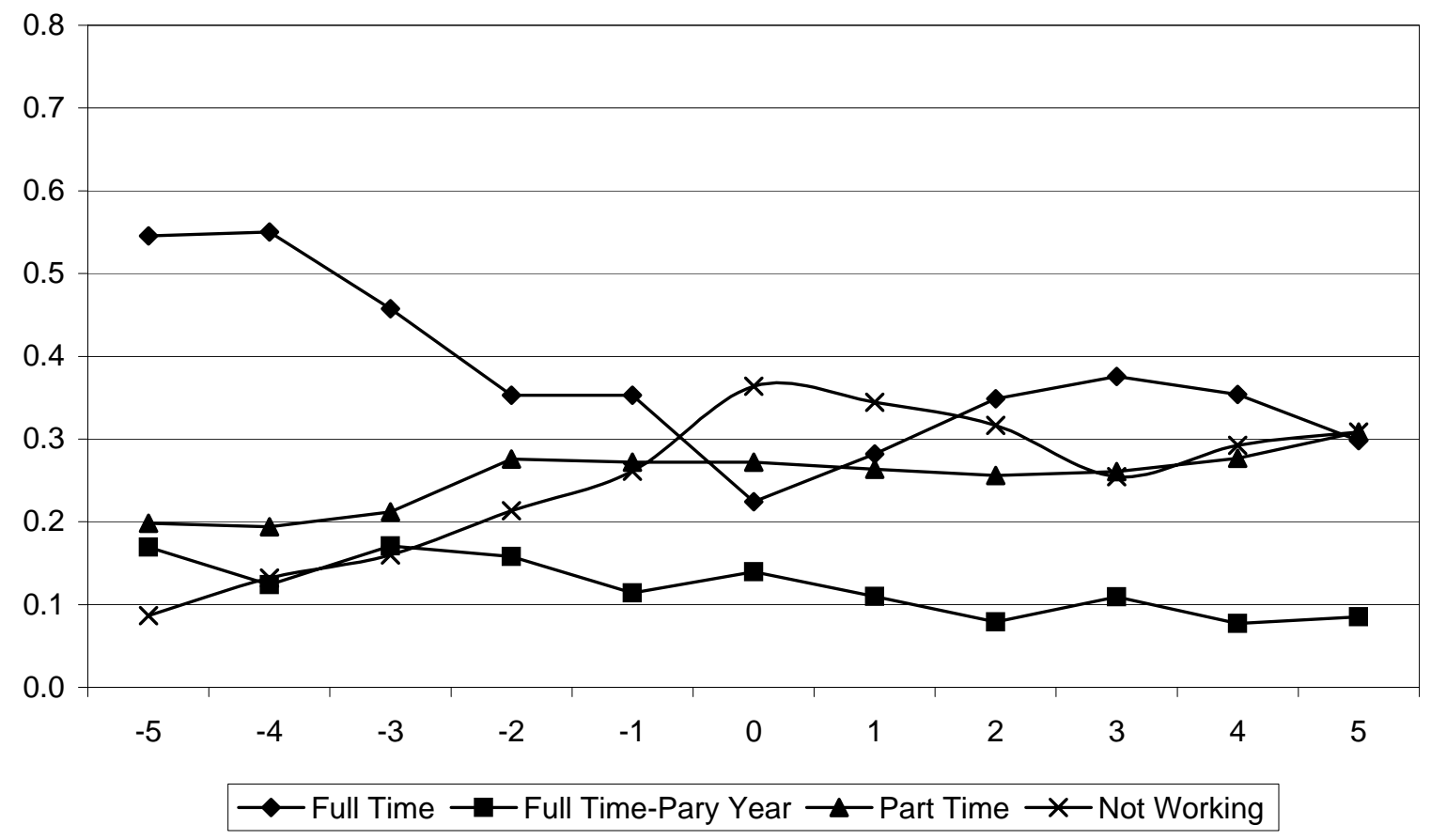


Figure 5-Labor Force Participation Rates for Women with 3 Children by 1993

First Birth

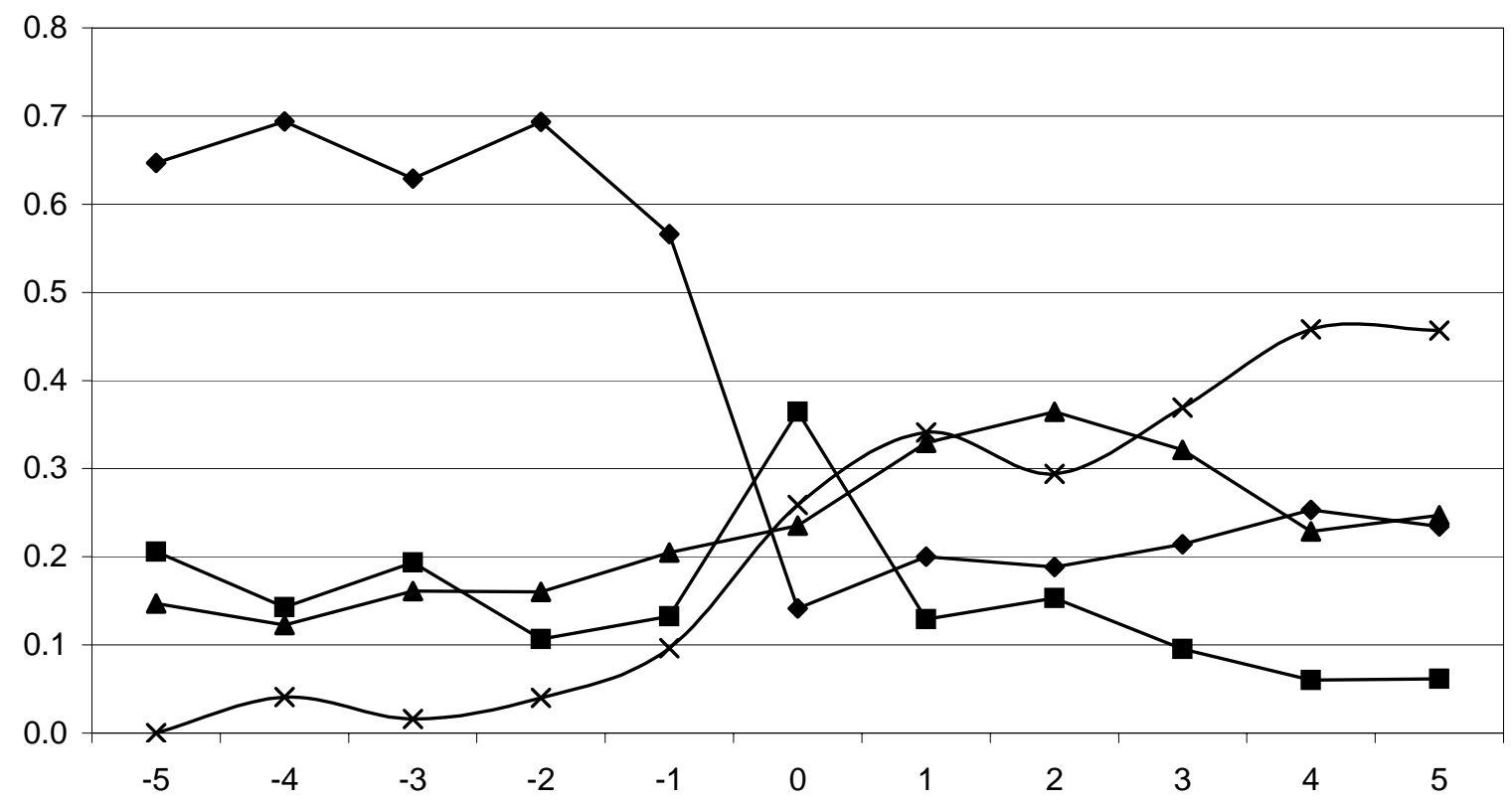

Third Birth

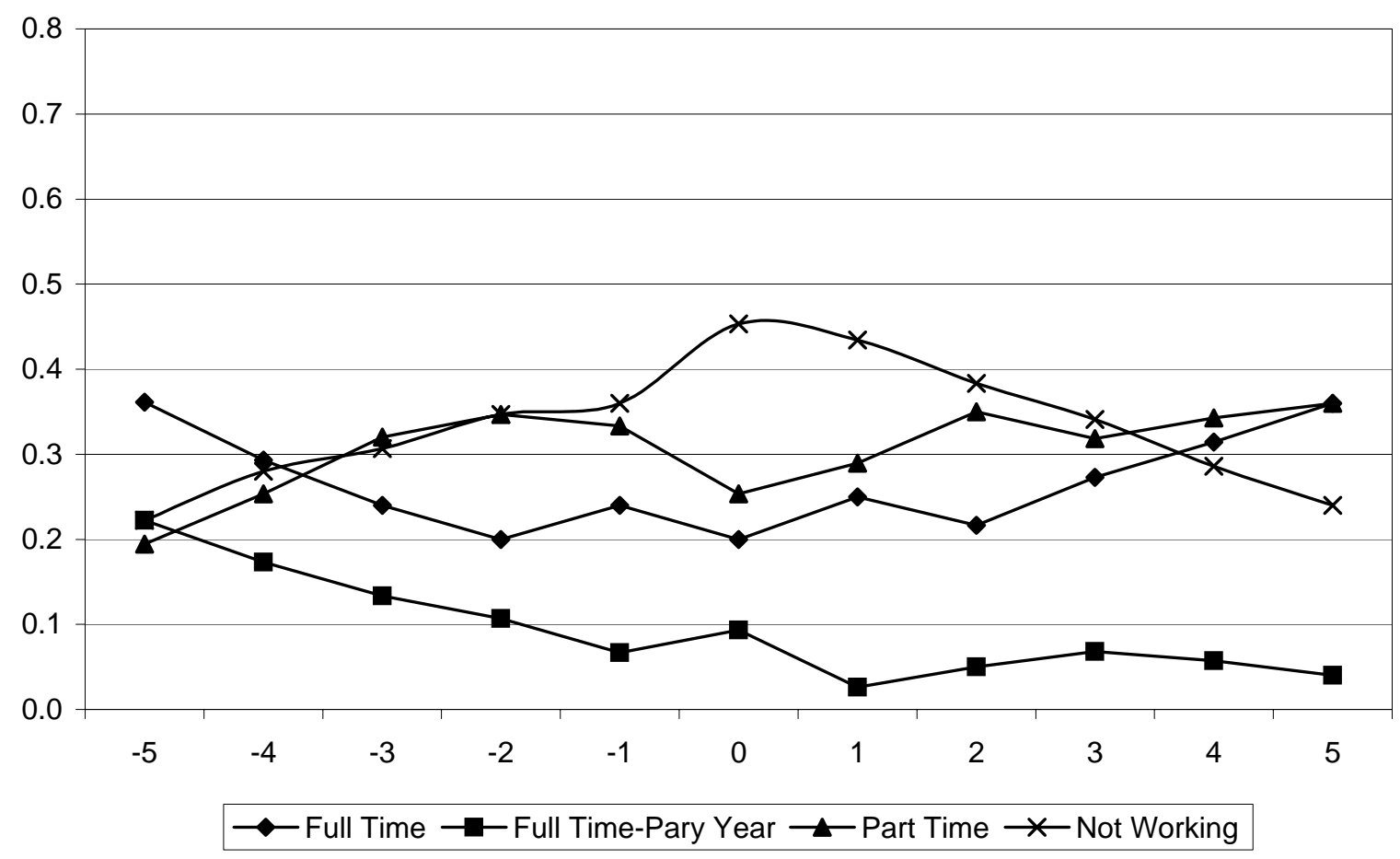


Figure 6: Probablity of Working Full-time by Likely Number of Children For White Women with Education <= 12 years

\section{A. Women Who Actually Have Zero Children}

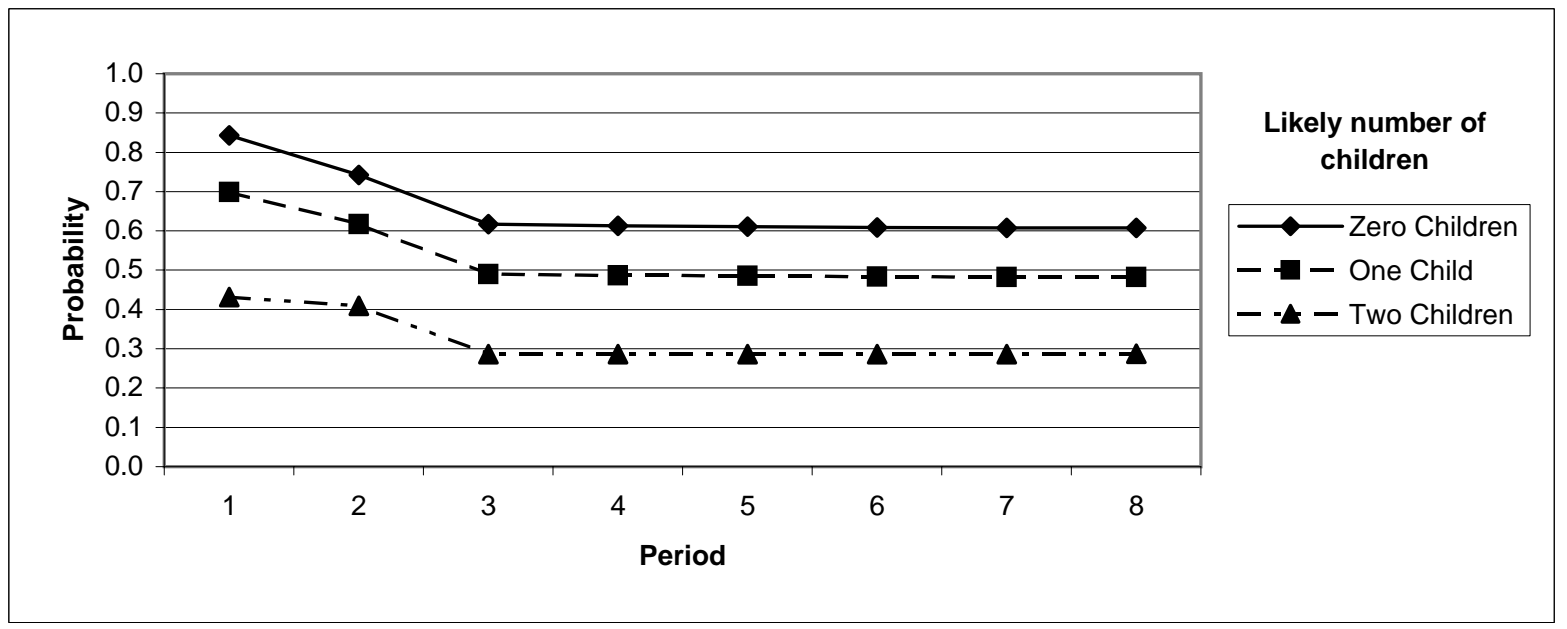

B. Women Who Actually Have One Child

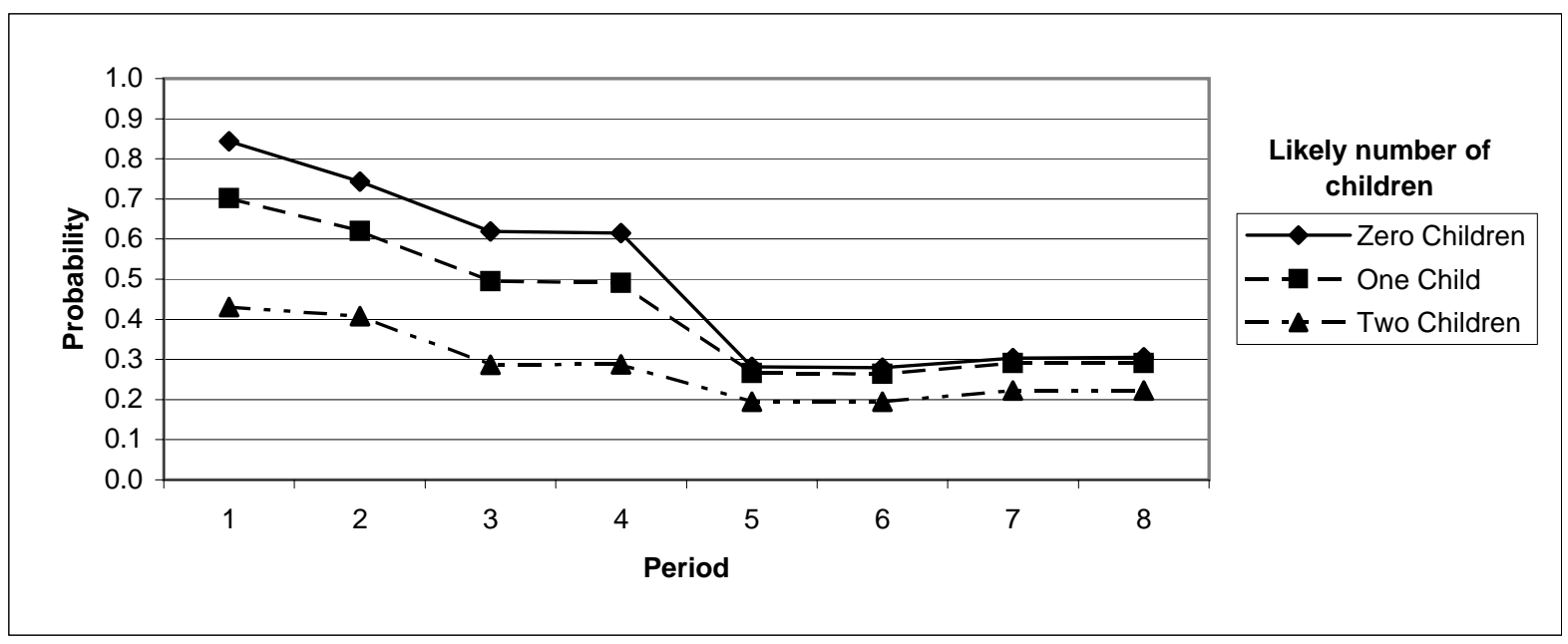

C. Women Who Actually Have Two Children

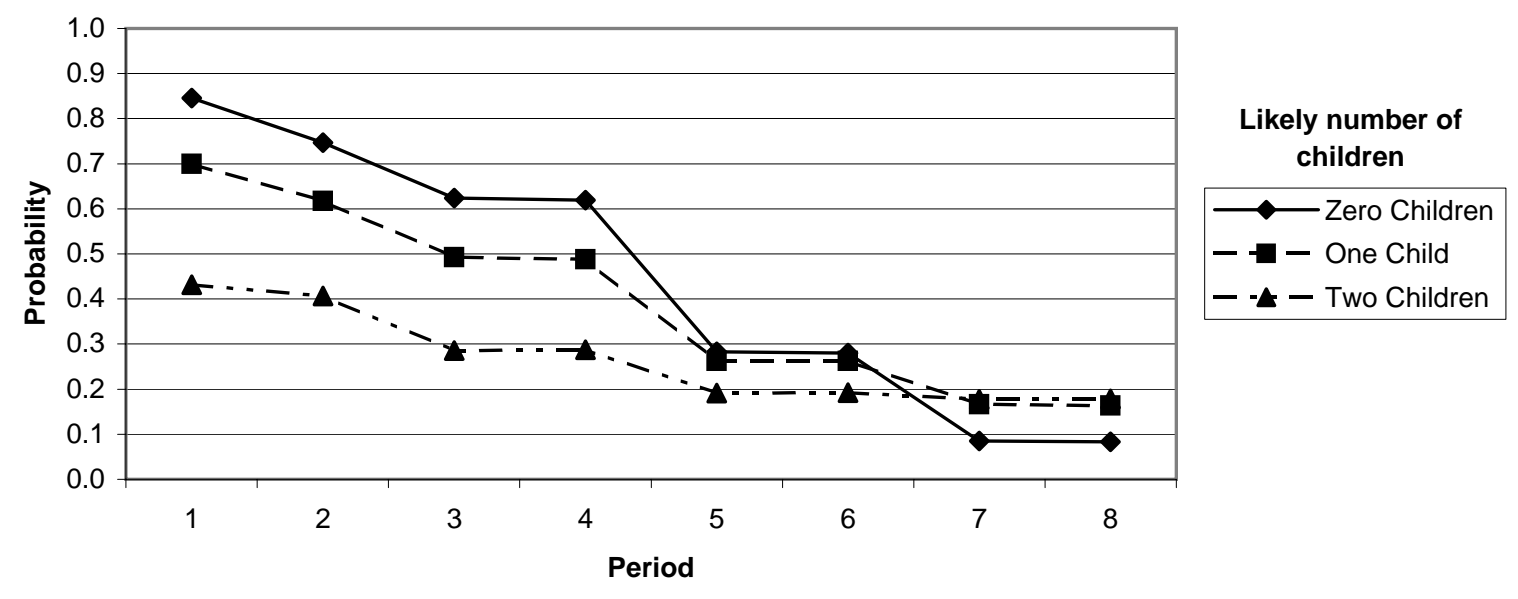

Note: In each of these simulations women get married in year 3 . Women who have one child do so in year 5 while women who have two children do so in years 5 and 8. 
Figure 7: Probablity of Working Full-time by Likely Number of Children For White Women with Education between 13 to 15 years

\section{A. Women Who Actually Have Zero Children}

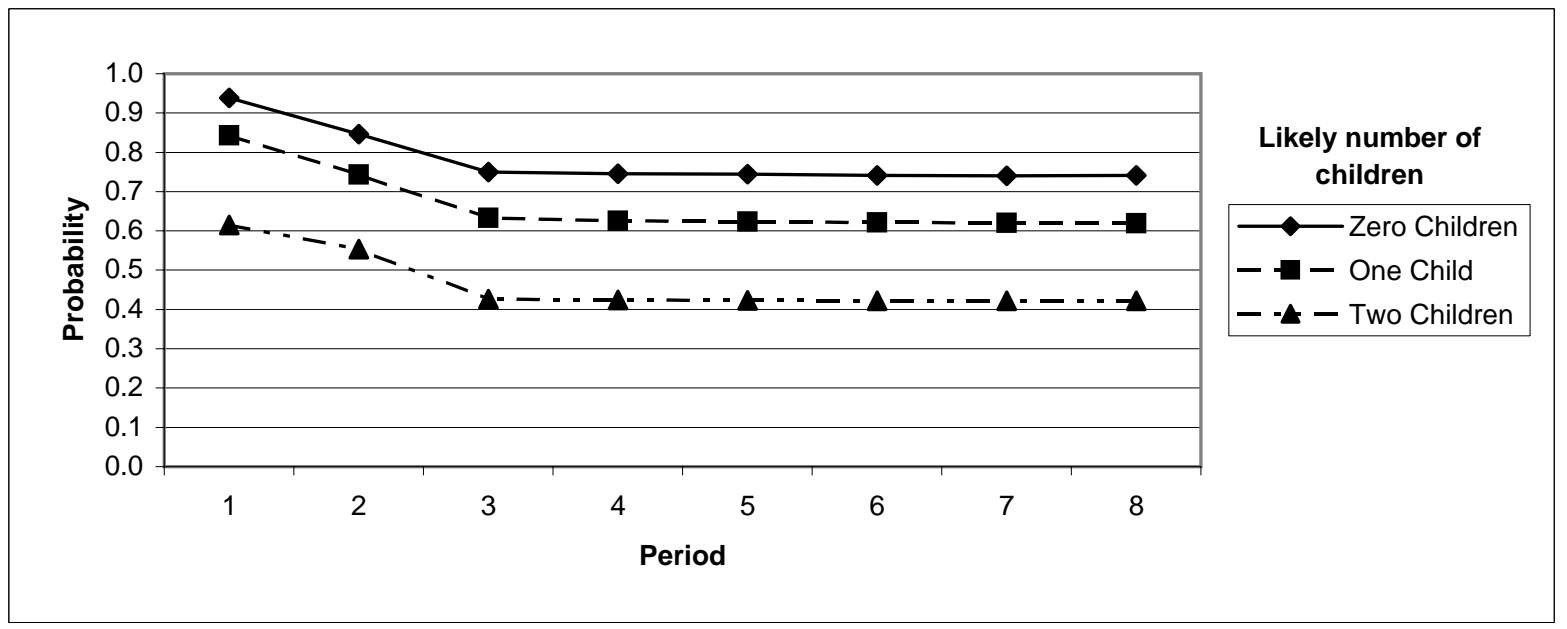

B. Women Who ActuallyHave One Child

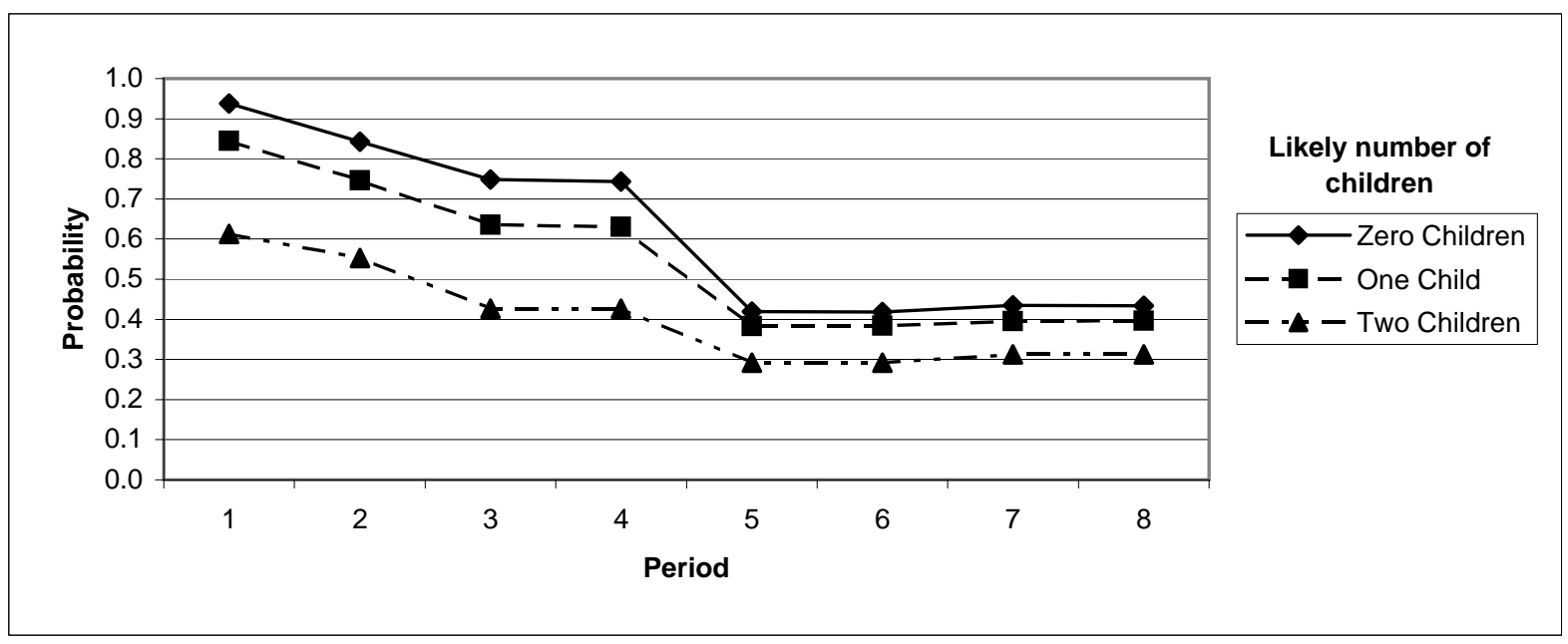

C. Women Who ActuallyHave Two Children

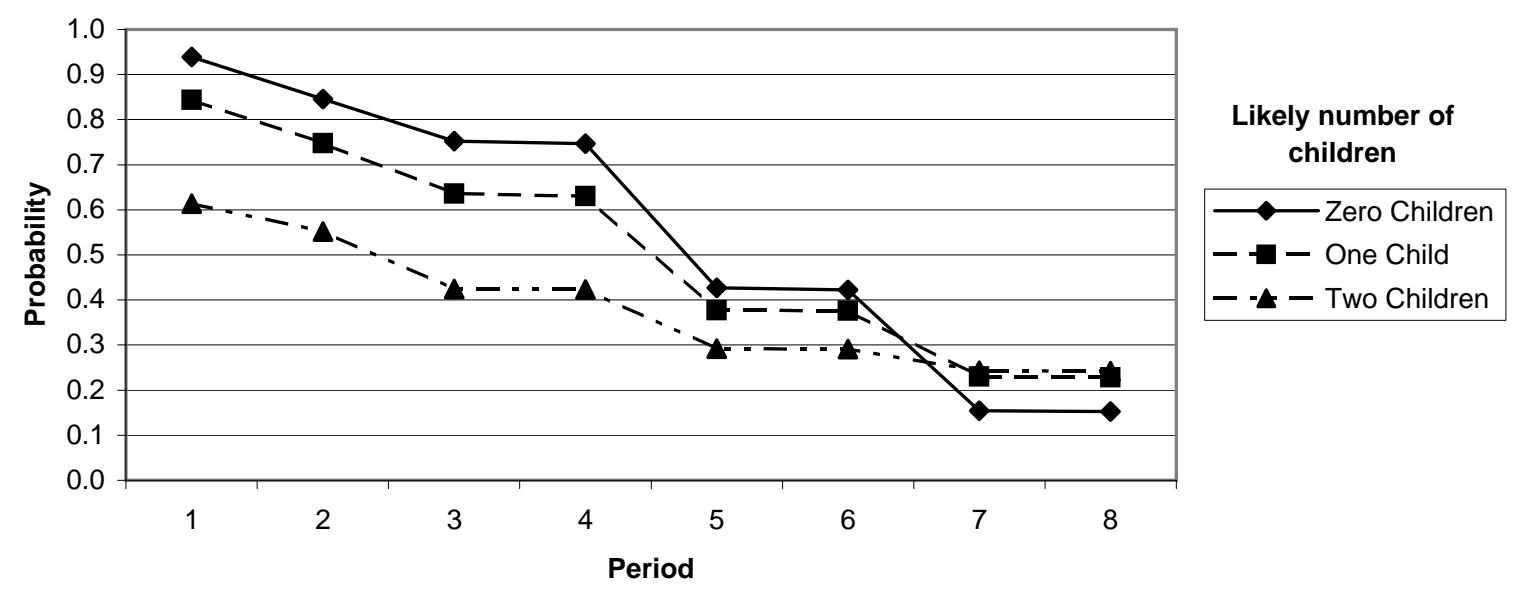

Note: In each of these simulations women get married in year 3 . Women who have one child do so in year 5 while women who have two children do so in years 5 and 8. 
Figure 8: Probablity of Working Full-time by Likely Number of Children For White Women with Education $>=16$ years

A. Women Who ActuallyHave Zero Children

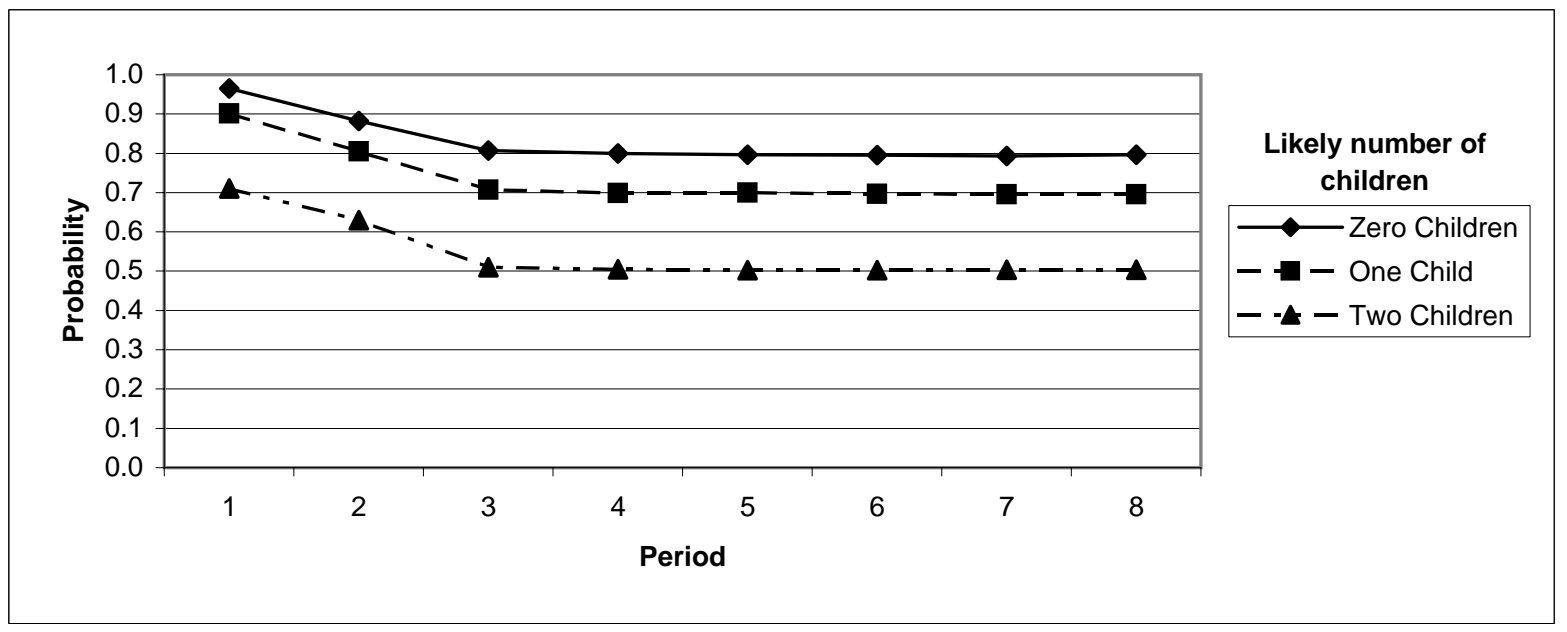

B. Women Who ActuallyHave One Child

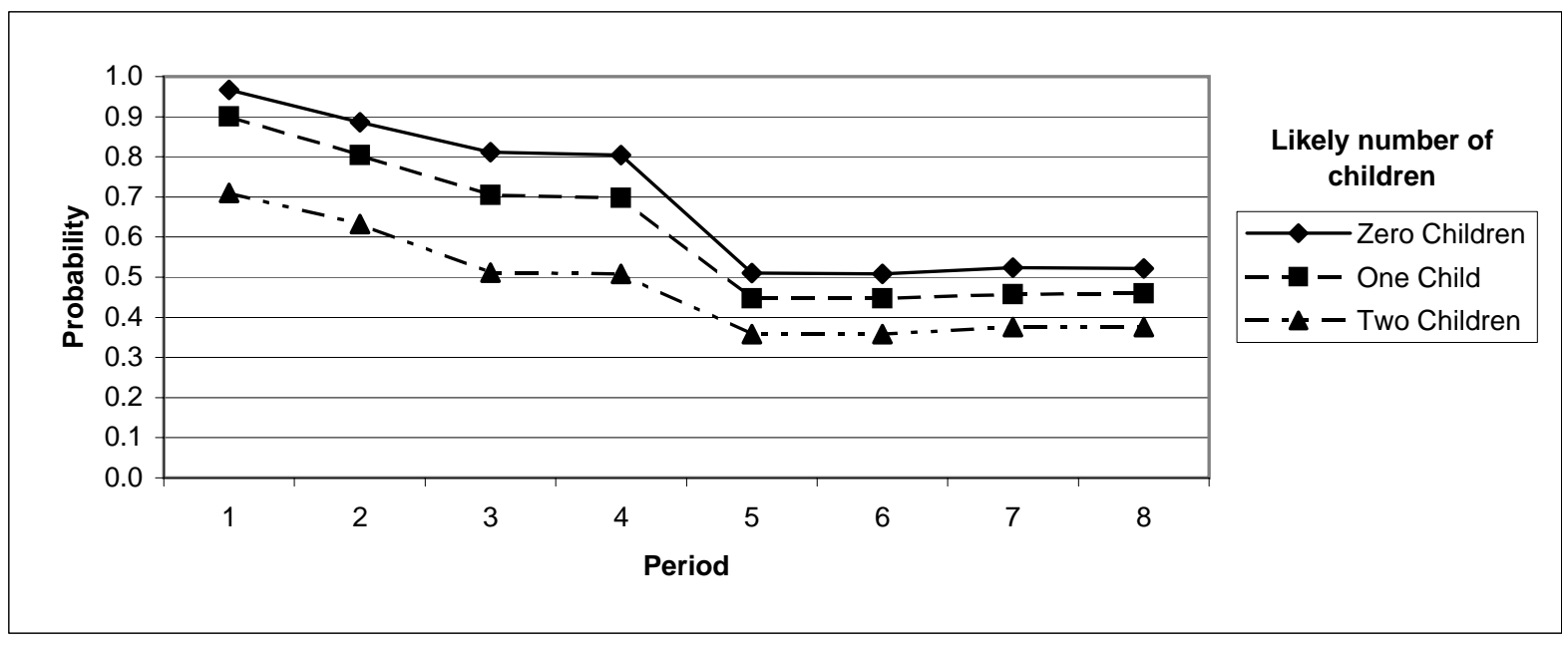

C. Women Who Actually Have Two Children

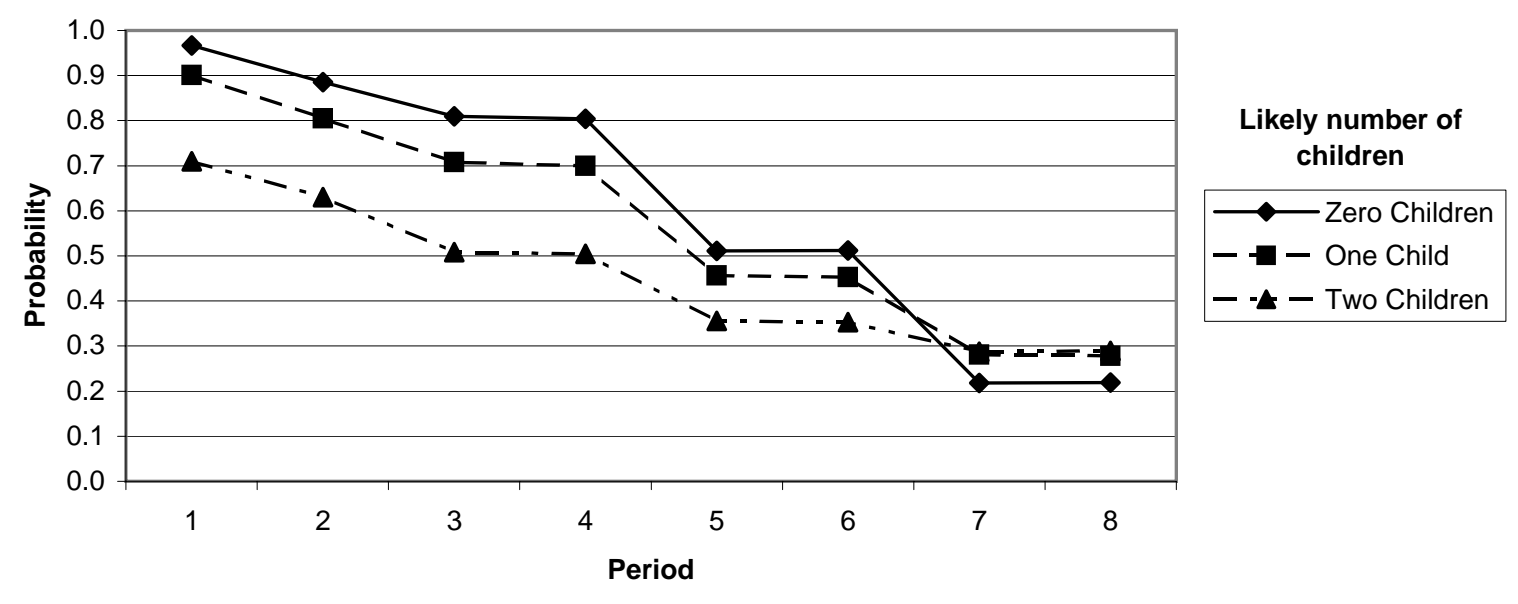

Note: In each of these simulations women get married in year 3 . Women who have one child do so in year 5 while women who have two children do so in years 5 and 8. 
Figure 9: Probablity of Working Full-time by Education For White Women with Two Children

A. Women Likely to Have Zero Children

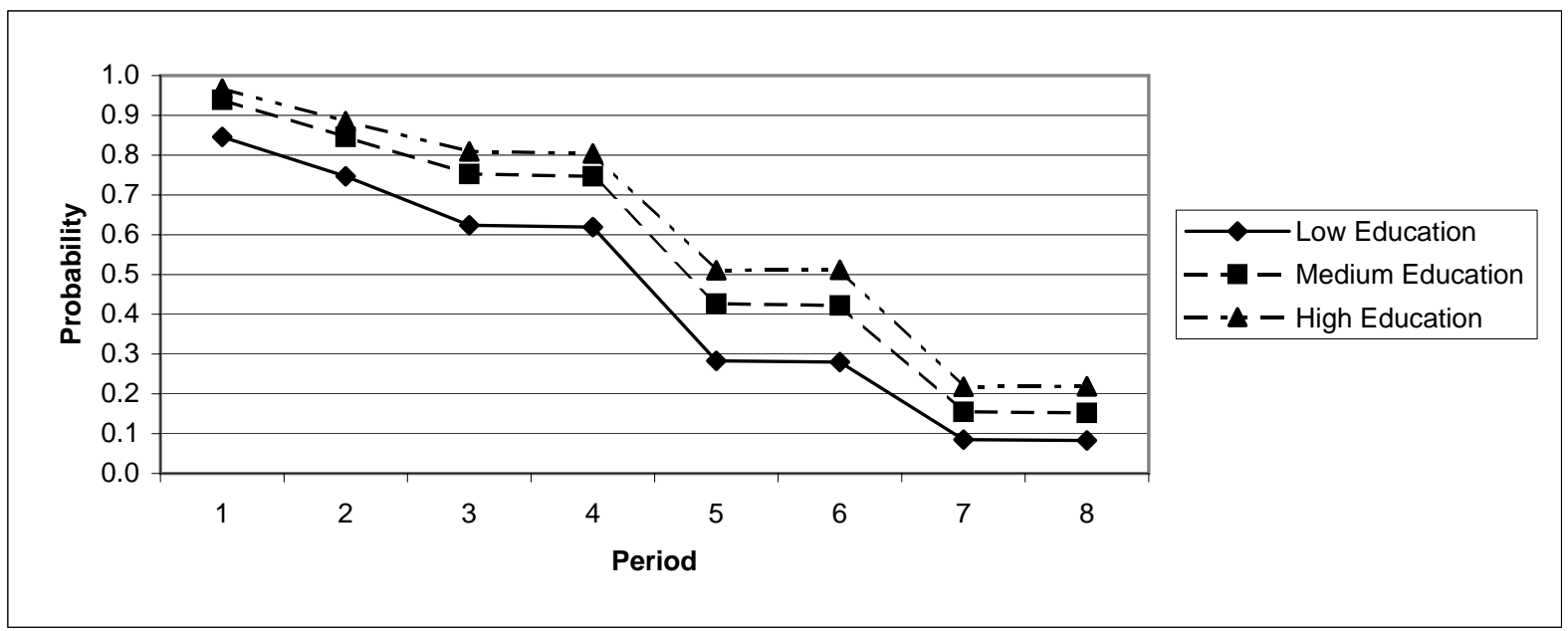

B. Women Likely to Have One Child

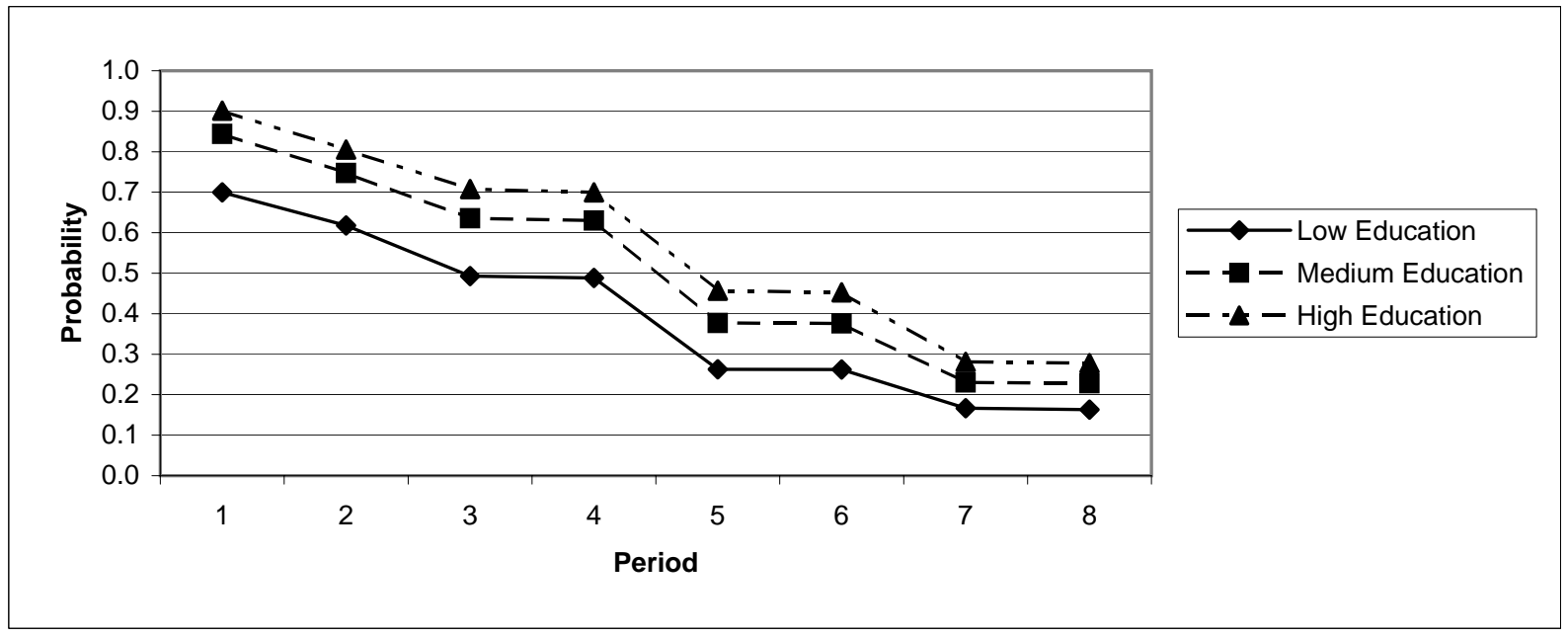

C. Women Likely to Have Two Children

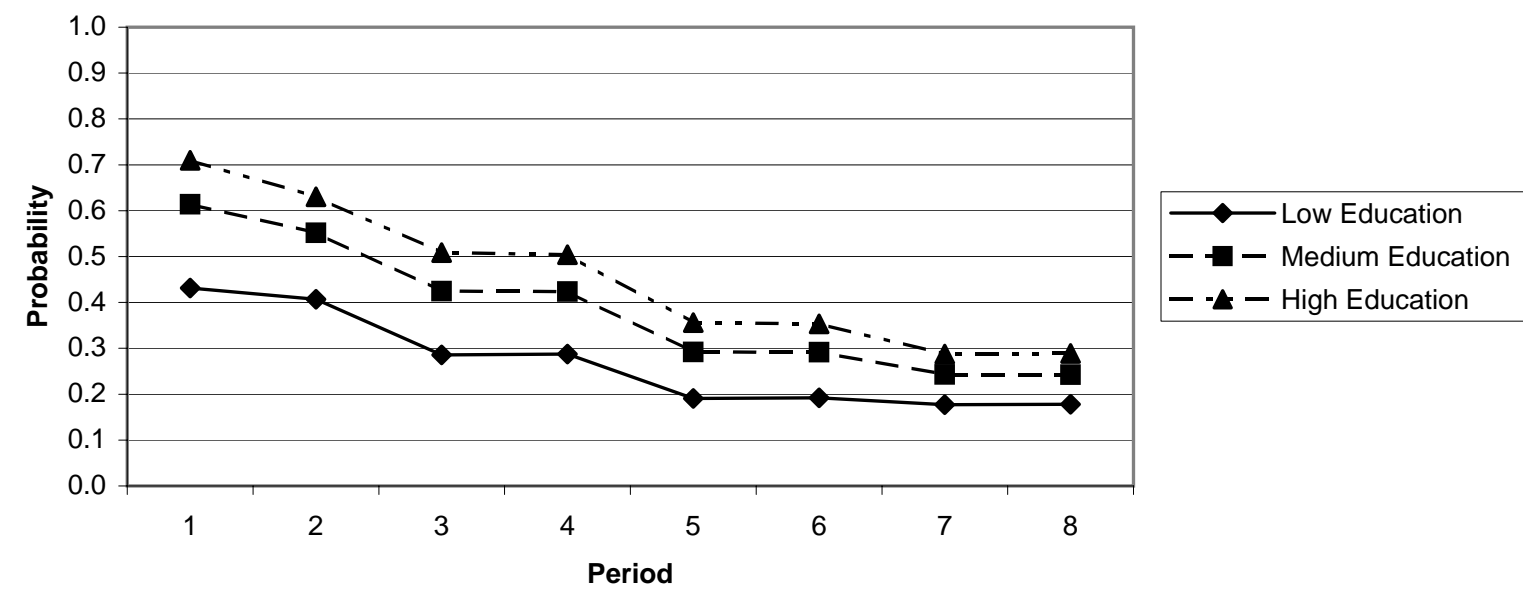

Note: In each of these simulations women get married in year 3 . Women who have one child do so in year 5 while women who have two children do so in years 5 and 8. 
Figure 10: Probablity of Working Full-time by Race For Women with Two Children A. Women Likely to Have Zero Children

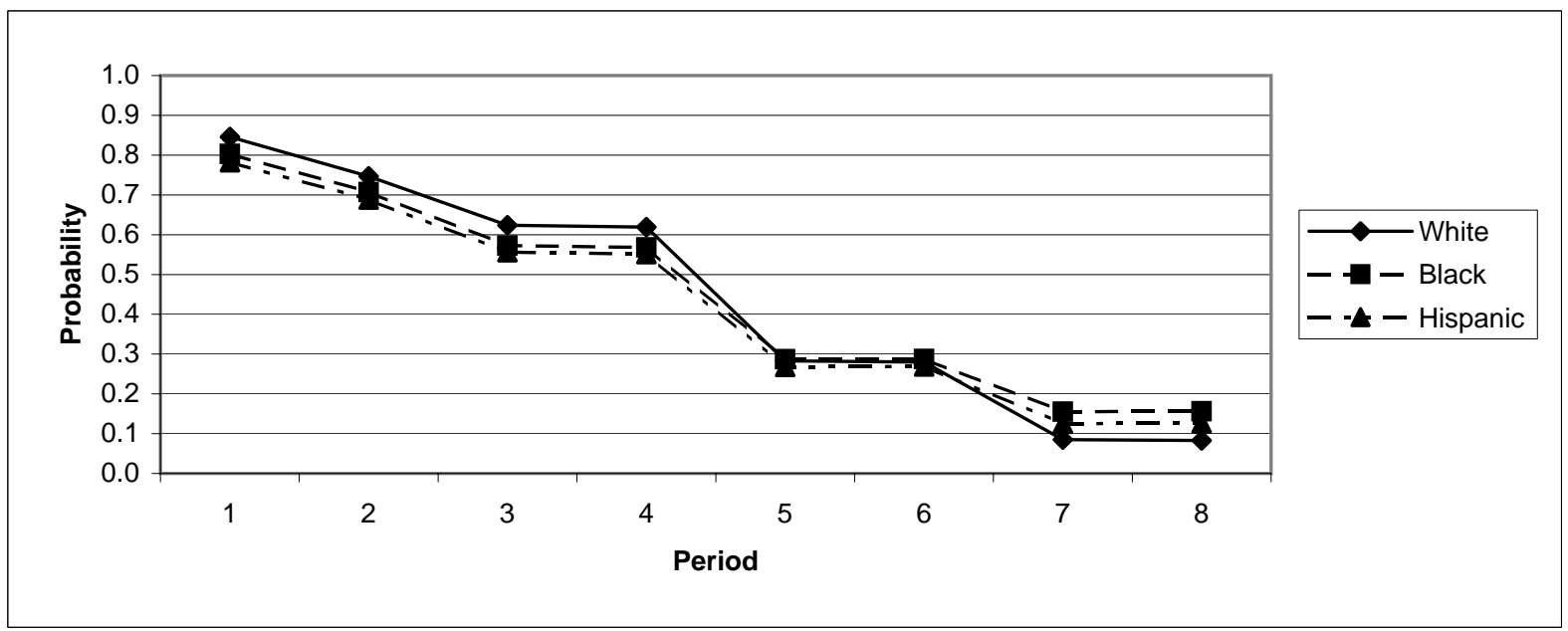

B. Women Likely to Have One Child

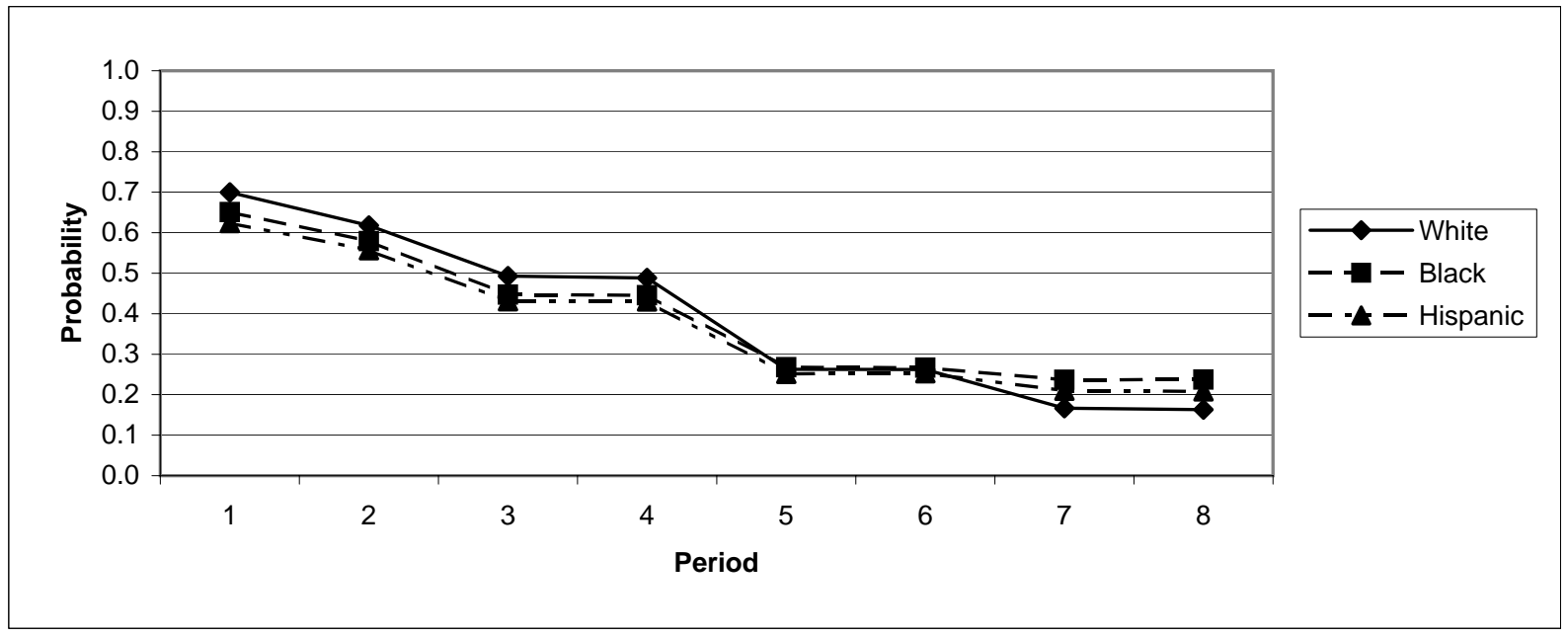

C. Women Likely to Have Two Children

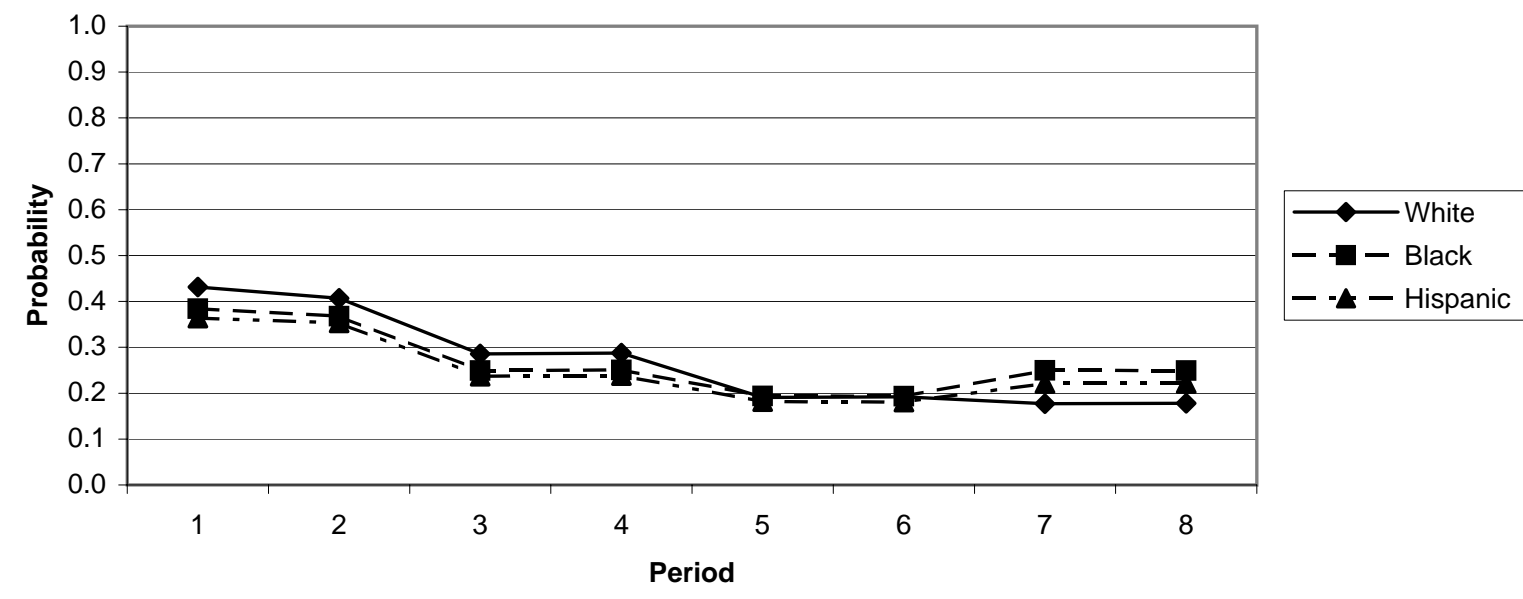

Note: In each of these simulations women get married in year 3 . Women who have one child do so in year 5 while women who have two children do so in years 5 and 8. 